\title{
Interaction of Stimulus-Driven Reorienting and Expectation in Ventral and Dorsal Frontoparietal and Basal Ganglia- Cortical Networks
}

\author{
Gordon L. Shulman, ${ }^{1}$ Serguei V. Astafiev, ${ }^{2}$ Danny Franke, ${ }^{2}$ Daniel L. W. Pope, ${ }^{1}$ Abraham Z. Snyder, ${ }^{2}$ Mark P. McAvoy, ${ }^{2}$ \\ and Maurizio Corbetta ${ }^{1,2,3}$ \\ Departments of ${ }^{1}$ Neurology, ${ }^{2}$ Radiology, and ${ }^{3}$ Anatomy and Neurobiology, Washington University, St. Louis, Missouri 63110
}

\begin{abstract}
Shifts of attention to unattended stimuli (stimulus-driven reorienting) are often studied by measuring responses to unexpected stimuli, confounding reorienting and expectation. We separately measured the blood-oxygenation-level-dependent signal for both factors by manipulating the probability of salient visual cues that either shifted attention away from or maintained attention on a stream of visual stimuli. The results distinguished three networks recruited by reorienting. Right temporoparietal junction (TPJ), the posterior core of a ventral frontoparietal network, was activated more by cues for shifting than maintaining attention independently of cue location and probability, acting as a switch. TPJ was separately modulated by low probability cues, which signaled a breach of spatial expectation, independently of whether they shifted attention. Under resting conditions, TPJ activity was correlated [resting-state functional connectivity magnetic resonance imaging, (rs-fcMRI)] with right inferior frontal gyrus (IFG), an anterior component of the ventral network. Nevertheless, IFG was activated only by unexpected shifts of attention, dissociating its function from TPJ. Basal ganglia and frontal/insula regions also were activated only when reorienting was unexpected but showed strong rs-fcMRI among themselves, not with TPJ/IFG, defining a distinct network that may retrieve/activate commands for shifting attention. Within dorsal frontoparietal regions, shifting attention produced sustained spatially selective modulations in intraparietal sulcus (IPS) and frontal-eye field (FEF), and transient less selective modulations in precuneus and FEF. Modulations were observed even when reorienting was likely, but increased when reorienting was unexpected. The latter result may partly reflect interactions with lateral prefrontal components of the basal-ganglia/frontal/ insula network that showed significant rs-fcMRI with the dorsal network.
\end{abstract}

\section{Introduction}

Survival can depend on quickly responding to behaviorally important objects that appear outside the focus of attention, a process here called stimulus-driven reorienting (Corbetta and Shulman, 2002). Because important unattended objects are often unexpected, however, understanding the function of neural systems during stimulus-driven reorienting requires a knowledge of how those systems are modulated by both shifts of attention and the likelihood of shifting attention. Unfortunately, previous studies have largely confounded these factors.

Stimulus-driven reorienting has often been studied using "oddball" (Marois et al., 2000) and Posner cueing paradigms (Arrington et al., 2000; Corbetta et al., 2000; Macaluso et al., 2002), which ensure that targets are unattended by making them unexpected. Larger blood-oxygenation-level-dependent (BOLD) responses to unexpected/unattended targets are consistently reported in right (R) TPJ and R ventral frontal cortex (VFC), whose

Received Nov. 24, 2008; revised Jan. 23, 2009; accepted Feb. 28, 2009.

This work was supported by National Institute of Neurological Disorders and Stroke Grant R01 NS048013, National Institute of Mental Health Grant R01 MH 71920 - 06, and the J. S. McDonnell Foundation.

Correspondence should be addressed to Gordon L. Shulman, Department of Neurology, Box 8111, 4525 Scott Avenue, Room 2109, St. Louis, M0 63110. E-mail: gordon@npg.wustl.edu.

DOI:10.1523/JNEUROSCI.5609-08.2009

Copyright $\odot 2009$ Society for Neuroscience $\quad$ 0270-6474/09/294392-16\$15.00/0 activity is highly correlated in the resting state (Fox et al., 2006), supporting proposals that they form a ventral attention network for stimulus-driven reorienting (Corbetta et al., 2008).

Previous studies have not identified separate roles for TPJ and VFC, but these regions may be dissociated when reorienting and expectation are factorially manipulated. Prefrontal regions may be recruited only when reorienting is unexpected and greater cognitive control is required (Fuster, 1989; Miller and Cohen, 2001). Under these conditions, commands to shift attention may be retrieved/activated in working memory and motor responses prepared under the current set may be inhibited (Nobre et al., 1999). In contrast, TPJ may be recruited whenever reorienting occurs, functioning as a reset mechanism that promotes the reorganization of task networks (Corbetta et al., 2008).

Phasic dopaminergic inputs to striatum (Schultz, 1998) have also been proposed to facilitate shifts of attention to unexpected, behaviorally important stimuli (Redgrave et al., 1999a,b; Horvitz, 2000; Zink et al., 2006). Accordingly, striatum is activated more by shifts of attention to infrequent than frequent peripheral stimuli (Zink et al., 2003). We manipulated both reorienting and the frequency of reorienting rather than frequency alone to determine whether basal ganglia showed an interaction pattern similar to that discussed above for prefrontal regions, possibly defining a role for cortical-basal ganglia loops (Alexander et al., 1986) in stimulus-driven reorienting. 


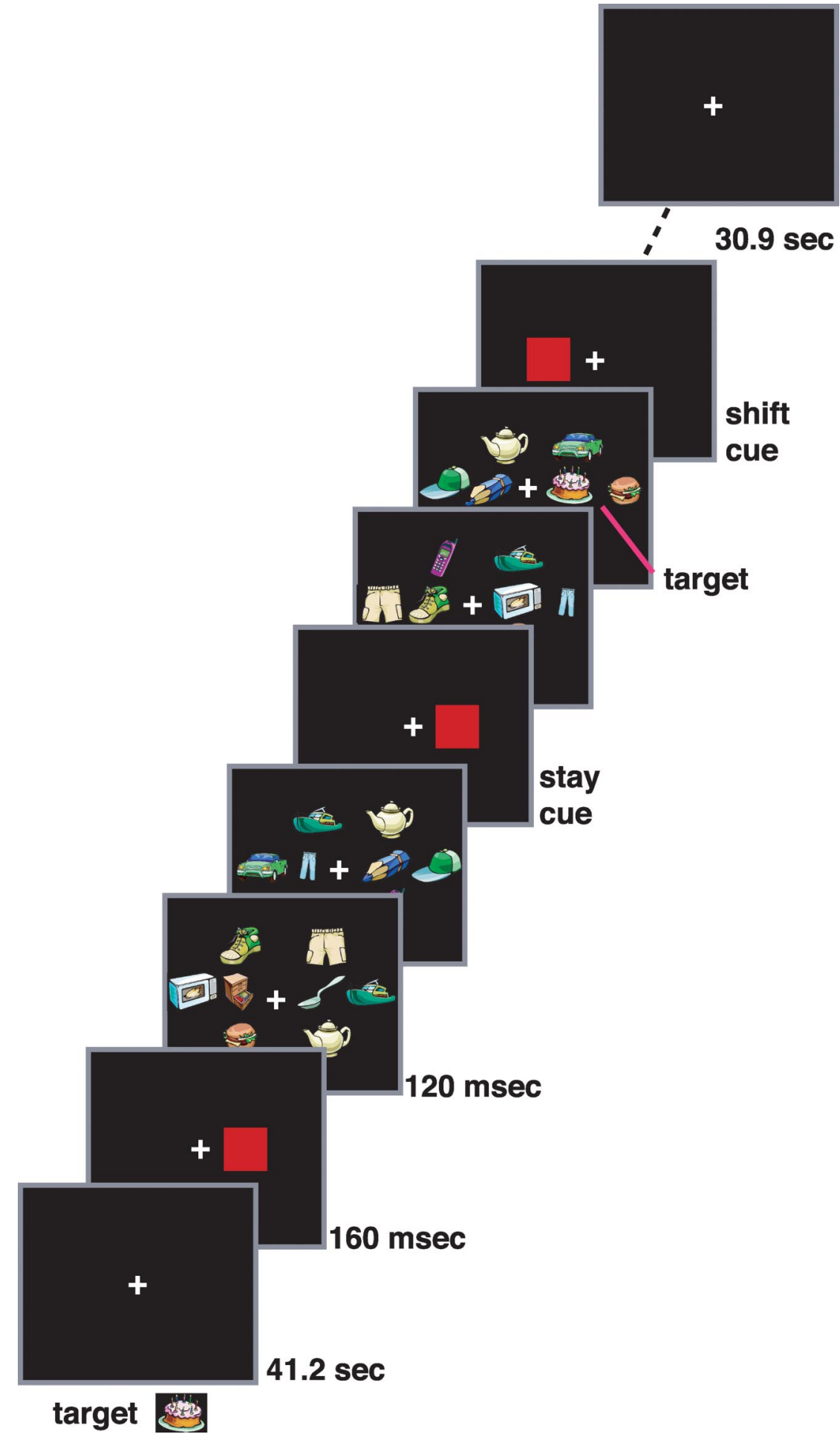

Figure 1. Procedure. The target object to be detected was presented at the beginning of the scan. Following a fixation period (41.2s), a red square (160 ms duration) cue indicated the RSVP stream in which targets would appear. Subsequent cues indicated targets would continue to appear in the currently attended stream (stay cues) or would appear in the opposite stream (shift cues). Successive cues were separated by $2.06,4.12$, or $6.18 \mathrm{~s}$ while successive targets were separated on average by $10.5 \mathrm{~s}$. The scan ended following a post-task fixation period ( $30.9 \mathrm{~s}$ ). Across scans, the probability of a shift versus stay cue was varied to manipulate expectation. See Materials and Methods (Procedure) for details.

While the ventral attention network is activated by stimulusdriven reorienting to important stimuli, a dorsal frontoparietal network is activated by orienting regardless of whether stimuli are present or absent (Kastner and Ungerleider, 2000; Corbetta and Shulman, 2002). This network likely implements the com- plex computations for shifting attention, sending biasing signals to sensory regions (Desimone and Duncan, 1995; Bisley and Goldberg, 2003; Moore and Armstrong, 2003; Ruff et al., 2006; Bressler et al., 2008). Because of their central role in shifting attention, dorsal frontoparietal regions should be activated even when reorienting is expected, but activations may increase when reorienting is unexpected and commands to shift attention must be assembled.

We evaluated the above hypotheses by factorially manipulating shifting/maintaining attention to stimuli and the likelihood of shifting/maintaining attention, and measured the resulting BOLD signals in ventral and dorsal attention networks, basal ganglia, and prefrontal regions.

\section{Materials and Methods \\ Paradigm}

Throughout the study, the term stimulusdriven reorienting is used to refer to shifts of attention evoked by cues presented outside the current focus of attention. Stimulus-driven reorienting can potentially involve both goaldriven and automatic (i.e., exogenous) components of reorienting, the latter isolated by measuring shifts of attention evoked by salient but noninformative or task-irrelevant cues (Posner and Cohen, 1984). However, previous studies have shown that TPJ activation during stimulus-driven reorienting primarily reflects goal-driven rather than exogenous shifts of attention (Downar et al., 2001; de Fockert et al., 2004; Kincade et al., 2005; Serences et al., 2005; Indovina and Macaluso, 2007) (for review, see Corbetta et al., 2008). Therefore, we do not use the term stimulus-driven reorienting to refer to automatic shifts of attention but more generally to refer to shifts of attention to stimuli outside the current focus of attention.

We manipulated the probability of cues that shifted attention or maintained attention at the current location within a factorial design, and measured the resulting BOLD signals. Subjects searched for a target object in two task-relevant rapid-serial-visual-presentation (RSVP) streams, one left and one right of fixation (Fig. 1). Each stream was flanked by three irrelevant distracter RSVP streams to increase the need for careful spatial selection. A salient, easily detectable cue stimulus (a filled red square) presented without accompanying objects in one of the task-relevant RSVP streams indicated which of the two streams contained the target. The cue was presented multiple times over a block. A cue might occur in the same stream as the previous cue, indicating that subjects should continue to monitor the same stream (a "stay" cue) or it might occur in the opposite, unattended stream, indicating that subjects should shift their attention to the new stream (a "shift" cue). Target identification was set at difficult levels (see below). The high difficulty of the target discrimination and the presence of distracter streams, coupled with the high salience of the cue stimulus, encouraged subjects to attend closely to the cued stream rather than 
distributing attention across both streams. In one set of scans, a cue was highly likely to occur in the same stream as the previous cue (i.e., the probability that the cue was a stay cue was 0.86 ), in another set of scans, a cue was highly likely to occur in a different stream than the previous cue (i.e., the probability that the cue was a shift cue was 0.86 ), while in a third set, stay and shift cues were equally likely. This design, a modification of earlier stay/shift paradigms (Yantis et al., 2002) in which symbolic cues at the current location of attention instructed stay or shift, allowed a factorial manipulation of stimulus-driven reorienting and expectation.

The experimental design controlled for several processes that are separate from stimulus-driven reorienting, in addition to expectation. Activations were measured to a cue that indicated where but not when a target would appear, eliminating time-locked activations related to temporal prediction of target onset (Coull and Nobre, 1998; Coull et al., 2000), including those involving a heightened state of alertness or motor preparation. Second, activations were measured to cues rather than to targets requiring a detection response. When a target detection response is overt, time-locked activations may occur that are related to response selection, response execution, performance monitoring, and the interaction of these processes with expectation (e.g., selecting/executing an unexpected as compared with an expected stimulus-response mapping likely increases activations in some areas). When a detection response is covert, such as counting, time-locked activations may occur related to the covert process (e.g., incrementing a counter and maintaining it in working memory), performance monitoring, and the interaction of these processes with expectation. The present experimental design isolated effects of reorienting and expectation that were separate from these target- and response-related processes.

\section{Subjects and stimuli}

Thirty-five right-handed subjects gave informed consent in accordance with guidelines set by the Human Studies Committee of Washington University. Twenty-four subjects participated in the RSVP experiment, but data were eliminated from two subjects due to eye movements and one subject due to movement artifacts. Eleven subjects participated in the resting-state connectivity experiment.

Stimuli were presented with a Power Macintosh G4 computer (Apple) using Matlab software (Mathworks) with the psychophysics toolbox (Brainard, 1997; Pelli, 1997). Images were projected to the head of the bore of the scanner via a liquid crystal display projector (Sharp LCD C20X) and viewed with a mirror attached to the head coil.

Four RSVP streams of colored drawings of inanimate objects were presented in the left visual field and four in the right visual field (Fig. 1). The target streams, which could potentially contain the target object, were surrounded by three nontarget streams that contained only distracter objects. One nontarget stream was positioned above the target stream, one was below, and a third was more eccentric. The target streams were located at an eccentricity of 5 degrees (deg). All objects in both target and nontarget streams were $\sim 3$ deg by 3 deg. Distracter objects were sampled from a population of 40 objects and target objects were sampled from a separate population of 12 objects. The cue was a filled red square, $3 \mathrm{deg}$ by $3 \mathrm{deg}$, located in the target stream. None of the objects were red and when the cue was presented, no other objects were present in the field.

The discriminability of the target object was adjusted by adding colored noise to each object in the target streams in both fields (i.e., noise was added to both potential target streams, not only to the stream that was presently cued). To create the noise, a percentage of the pixels defining the target stream location in each field were randomly colored, with each pixel displayed in one of five randomly selected hues.

\section{Procedure}

Subjects were shown the target object, randomly selected from the 12 objects designated as targets, before each scan. The target object for a scan never appeared as a nontarget object in another scan. At the start of a scan, subjects fixated a central cross for $41.2 \mathrm{~s}$. A cue then appeared at one of the two target stream locations, indicating the initial stream to be attended. The eight RSVP streams then appeared. Each display frame of 8 objects was presented for $120 \mathrm{~ms}$, with no interstimulus interval (ISI) separating it from the next frame. Each cue appeared for $160 \mathrm{~ms}$, again with a $0 \mathrm{~ms}$ ISI before the next display frame. Subjects pressed an MR compatible button when they detected a target. Target objects only appeared in the cued stream. A target occurred with a fixed probability independently in each $1.08 \mathrm{~s}$ interval, such that on average a target occurred approximately once every $10.5 \mathrm{~s}$. To allow separate button presses to be recorded for each target, the minimum intertarget interval was restricted to $1 \mathrm{~s}$. Cues occurred on average every 2.06, 4.12, or $6.18 \mathrm{~s}$ within a temporal window of plus or minus $400 \mathrm{~ms}$ centered on those values. Cue onset and target onset were independent except that a target could not occur simultaneously with a cue or in the $120 \mathrm{~ms}$ display frame preceding a cue. Therefore, cues provided spatial information about targets but essentially no temporal information. Following the initial $41.2 \mathrm{~s}$ fixation period, the stimulus display was presented for $185.4 \mathrm{~s}$ and was followed by a $30.9 \mathrm{~s}$ fixation period, resulting in a scan duration of $257.5 \mathrm{~s}$.

Each subject received 16 scans. In six scans the probability of a stay cue was 0.14 (shift cue probability was 0.86 ), in four scans, stay cue probability was 0.5 (shift cue probability, 0.5 ) and in six scans stay cue probability was 0.86 (shift cue probability, 0.14 ). Subjects were informed before each scan that it was "mostly stay," "mostly shift," or "stay and shift equally likely."

Before the scanning session, each subject received a practice session in which the noise level (percentage of voxels randomly colored) was determined at which the task could be performed with a $60 \%$ target hit rate. This fraction was then decreased by 0.05 for the session in the scanner, since our experience was that subject performance was slightly worse in the scanner. During the scanning session, the fraction was occasionally varied for each subject to approximately maintain performance at a desired level, using the following rules: if the percentage of hits $<10$ on a scan, the noise fraction was lowered by 0.1 ; if the percentage of hits $<40$ on two consecutive scans, the noise was lowered by 0.1 ; if the percentage of hits $<50$ on three consecutive scans, the noise was lowered by 0.05 ; if the percentage of hits $>90$ on a scan, the noise fraction was raised by 0.05 ; if the percentage of hits $>80$ on two consecutive scans, the noise was raised by 0.05 ; if the percentage of hits $>70$ on three consecutive scans, the noise was raised by 0.05 .

\section{Eye movement recording}

To verify that subjects followed instructions to remain fixated, each subject's eyes were carefully monitored via a camera on all scans. Moreover, eye movements were recorded for each subject using an infrared eyetracking system on some scans during the scanner session (22 subjects, ISCAN ETL-200) or during a behavioral session outside of the scanner (two subjects, ASL 504). Eye movement data were lost for one subject because of technical difficulties.

\section{Functional magnetic resonance imaging methods}

Image acquisition. Magnetic resonance imaging (MRI) scans were collected on a Siemens Allegra 3T scanner, using a gradient-echo echoplanar imaging sequence to measure BOLD contrast. Thirty-two contiguous 4 $\mathrm{mm}$ slices were acquired, $4 \times 4 \mathrm{~mm}$ in-plane resolution, echo time $(\mathrm{TE})=25 \mathrm{~ms}$, flip angle $=90^{\circ}$, repetition time $(\mathrm{TR})=2.06 \mathrm{~s}$. Structural images included a sagittal MP-RAGE T1-weighted sequence $(\mathrm{TR}=1810$ $\mathrm{ms}$, TE $=3.93 \mathrm{~ms}$, flip angle $=12^{\circ}$, inversion time $=1200 \mathrm{~ms}$, voxel size $=1 \times 1 \times 1.25 \mathrm{~mm}$ ).

Preprocessing. Differences in the acquisition time of each slice in an MR frame were compensated by sinc interpolation so that all slices were aligned to the start of the frame. A whole-brain normalization corrected for changes in signal intensity across scans. Data were realigned within and across scans to correct for head movement. Images were resampled into $3 \mathrm{~mm}$ isotropic voxels and warped into a standardized atlas space (Talairach and Tournoux, 1988). The resampling required for movement correction and atlas transformation was performed in the same step to minimize sampling noise.

Statistical analysis. The BOLD signal during the $185.6 \mathrm{~s}$ task period was analyzed with the general linear model (GLM). Four cue regressors (stay left, stay right, shift left, and shift right), each consisting of 10 separate time point regressors that estimated the hemodynamic response out to $18.5 \mathrm{~s}$ without assuming a response shape (Ollinger et al., 2001), were 
estimated for each probability condition (i.e., stay cue probability $=0.14$, 0.50 , and 0.86 ). Four sets of target time point regressors, not separated by cue probability, were also estimated: detected target left and right, missed target left and right. In addition, regressors were included for baseline, linear trend and low frequency components $(<.009 \mathrm{~Hz})$ of the BOLD signal in each scan.

The resulting whole-brain maps of time courses for cues and targets were smoothed by a Gaussian filter with a full-width-at-half-maximum of $6 \mathrm{~mm}$ and analyzed by ANOVAs in which subject was treated as a random effect. All voxelwise ANOVAs were corrected for nonindependence of time points by adjusting the degrees of freedom and corrected over the brain for multiple comparisons using joint $z$-score/cluster size thresholds (Forman et al., 1995) corresponding to $z=3.0$ and a cluster size of 13 face-contiguous voxels. The $z$-score/cluster size thresholds were determined using volume-based monte-carlo simulations. Regional ANOVAs were conducted on regions-of-interest (ROIs) that were automatically created from the voxel-level maps using a peak-finding routine (Kerr et al., 2004). For each subject and ROI, the BOLD time courses for a condition were averaged over all voxels in the ROI, and the regional time course for each condition was entered into an ANOVA, which corrected for nonindependence of time points by adjusting the degrees of freedom. A significance threshold of $p<0.01$, uncorrected for the number of tested ROIs, was adopted for regional analyses. For display purposes, volumes were mapped to surface-based representations using the PALS atlas and CARET software (Van Essen, 2005).

\section{Resting state functional connectivity MRI}

To determine whether regions that showed specific task modulations formed consistent networks, resting-state functional connectivity MRI (rs-fcMRI) of the task-evoked foci in these regions were evaluated in an independent group of 11 subjects. Rs-fcMRI assesses the temporal correlation between BOLD timeseries in different regions under conditions in which subjects are lying at rest with no experimenter-imposed task. Regions that are coactivated in task activation studies of attention show strong rs-fcMRI (Fox et al., 2006), replicating the putative dorsal and ventral attention networks (Corbetta and Shulman, 2002). Therefore, rs-fcMRI measures the degree to which regions form coherent networks in the resting state.

Rs-fcMRI maps were computed using previously published methods (Fox et al., 2006; He et al., 2007). Each subject received six 264 s BOLD scans (aside from one subject, whose scan duration was $328 \mathrm{~s}$, and another subject who received only four $264 \mathrm{~s}$ scans), in which fixation was maintained on a central plus sign in an otherwise empty field. Several preprocessing steps were conducted on the BOLD timeseries in addition to those described above: (1) temporal filtering that retained frequencies in the $0.009-0.08 \mathrm{~Hz}$ band and (2) removal by linear regression of (i) six parameters obtained by correction of head motion, (ii) the signal averaged over the whole brain, excluding the ventricles, (iii) the signal over a ventricular region, and (iv) the signal from a white matter region. Temporal derivatives of these regressors were also included in the linear model, accounting for time-shifted versions of spurious variance.

Voxelwise analyses. A voxelwise map was computed for a single "seed" ROI, which was either a $6 \mathrm{~mm}$ (cortical regions) or $3 \mathrm{~mm}$ (basal ganglia) radius sphere centered at a particular Talairach coordinate, indicating the correlation of each voxel in the brain with the indicated ROI. A smaller seed ROI was used for basal ganglia to avoid contributions from adjacent structures. The BOLD time series was averaged over all voxels in the seed ROI, the voxelwise Pearson correlation coefficients between that ROI and all other voxels were computed, and the Fisher $z$-transform was applied. For a group statistical analysis of the voxelwise map, a onesample $t$ test with subject as a random-effect was computed on the Fisher $z$-transformed values and corrected for multiple comparisons using a $z$-score threshold of $z=3.0$ and a cluster size of 17 face-contiguous voxels.

Regional analyses. The significance of rs-fcMRI between two regions or ROIs was computed as follows. For each subject, the voxels within each ROI were averaged and a regional time course was computed. Then the correlation coefficient between the two regional time courses was computed and the Fisher $z$-transform was applied. Finally, a random-effects
1 -sample $t$ test was performed on the Fisher $z$-transformed values from the individual subjects. A significance threshold of $p<0.01$ was adopted for regional analyses, uncorrected for the number of ROI pairs that were tested. In addition to pairwise analyses, we also computed the average rs-fcMRI within sets of regions by averaging within each subject the Fisher $z$-transformed value for each ROI-ROI pair within the set. Similarly, we measured the rs-fcMRI between sets of regions by averaging the Fisher $z$-transformed values for all ROI-ROI pairs between sets, where each ROI in a pair comes from a different set.

\section{Results}

\section{Behavior}

Subjects detected on average $61.7 \%$ of targets, with a mean false alarm rate (number of false alarms per number of targets) of $4.7 \%$. The detection rate was well below ceiling, indicating that the task was quite difficult, but also well above the false alarm rate, indicating above chance performance. Mean correct reaction time (RT) was $596 \mathrm{~ms}$.

An ANOVA on percentage detection rates with cue probability (i.e., probability of the cue immediately preceding the target: $0.14,0.50,0.86$ ) and cue type (i.e., type of cue immediately preceding the target: stay, shift) as factors indicated no significant effect of cue probability $\left(F_{(2,40)}=1.77\right)$, target type $\left(F_{(1,20)}=\right.$ $0.37, \mathrm{~ns})$, or cue probability by cue type interaction $\left[F_{(2,40)}=\right.$ 1.71 , nonsignificant $(\mathrm{ns})]$. A similar ANOVA on RTs also yielded no effects: cue probability $\left(F_{(2,40)}=1.06\right)$, cue type $\left(F_{(1,20)}=0.70\right.$, $\mathrm{ns})$, cue probability by cue type interaction $\left(F_{(2,40)}=1.50, \mathrm{~ns}\right)$. These results indicate that attention to the cued stream was similar across conditions and that subjects did not prematurely shift attention to an uncued stream when shift cues were likely.

\section{Functional MRI}

For each set of regions thought to be involved in stimulus-driven reorienting, i.e., TPJ, frontal cortex and basal ganglia, and dorsal frontoparietal cortex, we examine the BOLD activations due to stimulus-driven reorienting, defined by significant differences between stay and shift cues, and then describe how those activations were modulated by expectation.

\section{Results for R TPJ}

\section{Modulations due to stimulus-driven reorienting}

$\mathrm{R}$ TPJ was activated by stimulus-driven reorienting. The left coronal slice in Figure $2 \mathrm{~A}$ displays voxels in R TPJ that showed significantly different time courses following shift and stay cues [i.e., voxels that showed a significant interaction of cue type (shift, stay) by time (10 time points)]. All voxelwise ANOVAs were corrected for multiple comparisons over the whole brain (see Materials and Methods). A strong activation was observed in R TPJ $(52,-49,17 ; z=6.45)$, which extended dorsally into the supramarginal gyrus (SMG) $(51,-45,32 ; z=5.62)$. No significant activations were observed in left (L) TPJ, consistent with the right hemisphere dominance that has previously been observed for this region during stimulus-driven reorienting (Corbetta and Shulman, 2002).

$\mathrm{R}$ TPJ activations during reorienting did not depend on the location of the cue, confirming previous results (Corbetta et al., 2000). A regional ANOVA conducted on the R TPJ ROI formed from the shift versus stay activation (i.e., the cue type by time map) indicated no significant interaction of cue type by cue location (left, right) by time $\left(F_{(9,180)}=0.67\right)$. The voxelwise map for the cue type by cue location by time interaction also showed no effects in R TPJ. The time course of R TPJ activation, shown in the leftmost graph of Figure 2, indicated a transient response to a shift cue, relative to a stay cue, at both cue locations. 


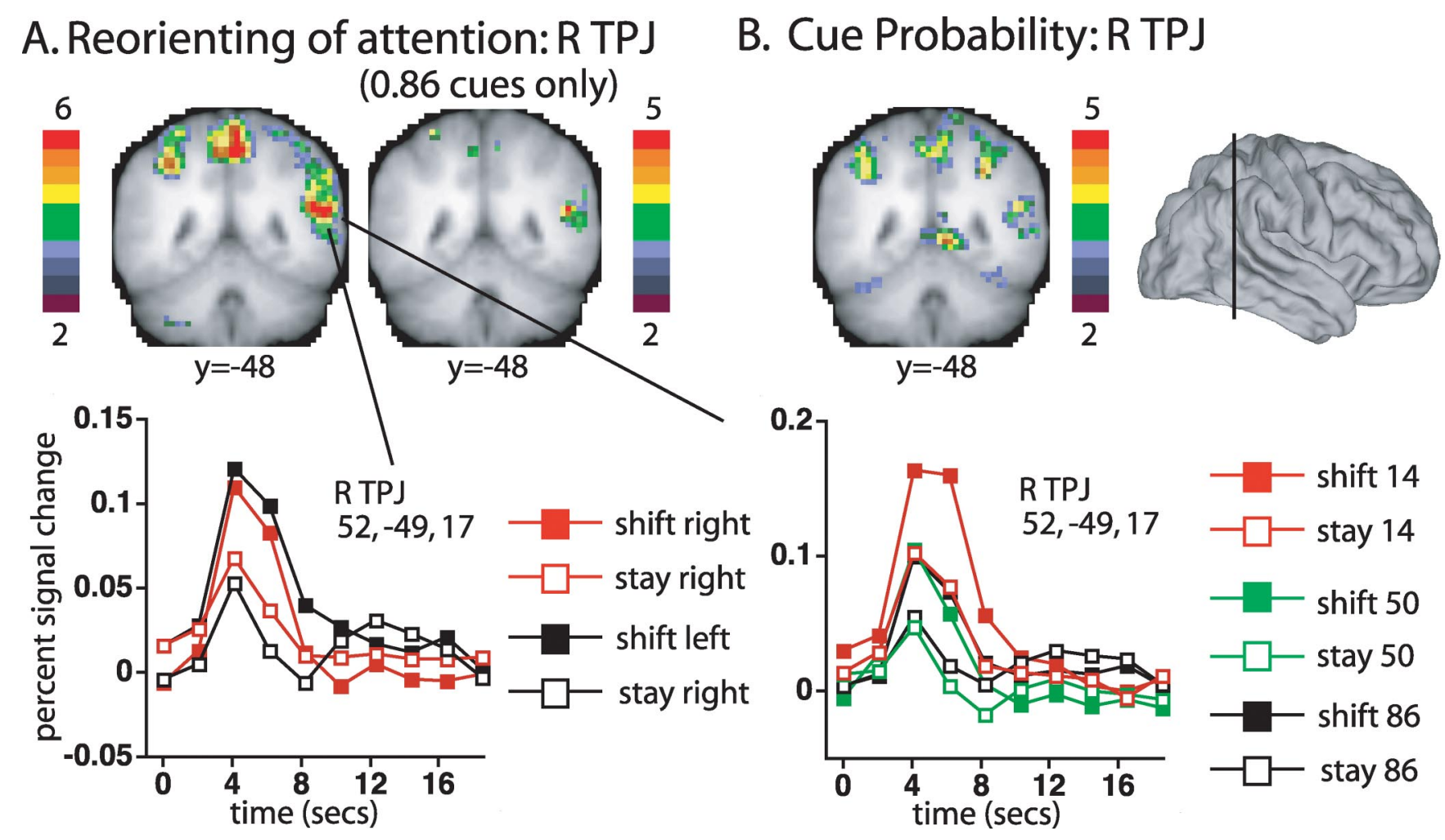

Figure 2. A, The left coronal slice shows voxels that showed significant differences between shift and stay cues (from the group cue type by time ANOVA map, corrected for multiple comparisons). The color bar indicates the equivalent $z$-score for the $p$ value from the ANOVA. The right coronal slice shows the corrected voxelwise map when only high probability (0.86) stay and shift conditions were included. The graphs show the time course of activation in the R TPJ ROI defined from the cue type by time map, as a function of cue type and cue location (left graph), or cue type and cue probability (right graph). B, Voxels that showed a significant effect of cue probability (coronal slice from the group cue probability $(0.86,0.50,0.14)$ by time ANOVA map, corrected for multiple comparisons). The line through the lateral surface view indicates the position of the coronal slice $y=-48$.

A difference between shift and stay cues was observed even when they were both highly likely. A voxelwise ANOVA, conducted on just the stay and shift cue data from the $p=0.86$ conditions yielded a significant cue type by time activation in $\mathrm{R}$ TPJ $(50,-49,14, z=4.88)$, as shown in Figure $2 \mathrm{~A}$.

\section{Modulations due to expectation}

$\mathrm{R}$ TPJ activity was affected by cue probability in addition to stimulus-driven reorienting. A regional ANOVA confirmed that the R TPJ ROI formed from the shift versus stay activation showed a significant interaction of cue probability $(0.14,0.50$, $0.86)$ by time $\left(F_{(18,360)}=3.91, p<0.0001\right)$. Moreover, the voxelwise map for the interaction of cue probability by time included a significant activation in R TPJ $(47,-48,17 ; z=5.18)$, shown in the coronal slice in Figure $2 B$, that was contained within the TPJ component of the more extensive shift versus stay activation. However, the cue probability and shift versus stay effects did not interact, i.e., were additive. A regional ANOVA on the shift versus stay ROI in R TPJ indicated no higher-order interaction of cue probability by cue type by time $\left(F_{(18,360)}=0.19\right)$, and no higherorder interaction was observed for R TPJ in the voxelwise map of the interaction.

Bolstering the evidence for separate reorienting and probability signals, R TPJ showed significant effects of cue probability even when the cue did not evoke a shift of attention. An analysis of the effect of cue probability in just the stay cue condition identified a significant voxelwise activation in R TPJ $(47,-52,14$; $z=3.75)$, and a significant effect in a regional ANOVA on the $\mathrm{R}$ TPJ ROI defined from the shift versus stay activation $\left(F_{(18,360)}=\right.$ $2.06, p=0.01)$.
The time course of R TPJ activation as a function of cue type and probability is shown in the right graph in Figure 2. Low probability cues (red symbols) produced larger activations than middle or high probability cues (green and black symbols) regardless of whether the cues signaled stay (open symbols) or shift (filled symbols). Notably, TPJ activity did not change linearly as a function of cue probability, with very similar responses for the medium and high probability cues (i.e., green and black symbols). This pattern indicates that R TPJ was activated when an expectation concerning the cue was breached, as in the low probability condition. A strong expectation was not present in the 0.50 condition, since stay and shift cues were equally likely, while the expectation in the 0.86 condition was confirmed rather than violated, leading to equivalent and lower activity in the latter two conditions. Voxelwise ANOVAs in which the cue probability factor was confined to the 0.14 and 0.50 conditions or to the 0.50 and 0.86 conditions confirmed that R TPJ was significantly activated by the former comparison $(46,-51,16, z=3.93)$ but not by the latter. Finally, the time courses supported the earlier conclusion that the reorienting and breach of expectation effects were additive. The BOLD signal in R TPJ was reasonably described by increments due to reorienting (shift 50 , shift 86), breached expectation (stay 14), or their sum (shift 14).

To summarize, R TPJ showed significant effects of stimulusdriven reorienting to either visual field even when shifts of attention were likely and frequently performed, and these activations were not increased when reorienting was unlikely. R TPJ was independently (additively) activated by low probability cues, indicating separate signals for reorienting and breaches of expecta- 
tion. R TPJ activations to unexpected targets in previous studies reflected a sum of reorienting and breach of expectation signals (Arrington et al., 2000; Corbetta et al., 2000; Marois et al., 2000; Macaluso et al., 2002).

\section{Results for frontal/insula cortex and basal ganglia}

In contrast to R TPJ, several regions in frontal and insula cortex and basal ganglia (Fig. $3 A, B$ ) were primarily activated by unexpected shift cues, resulting in a strong interaction of stimulusdriven reorienting and cue probability (see Table 1 for $z$-scores and coordinates of significant foci). Significant interactions in the voxelwise map for cue probability by cue type by time were observed in left anterior insula, anterior cingulate, and left dorsolateral prefrontal cortex (DLPFC) (Fig. 3A), and in basal ganglia (Fig. $3 B$ ), including bilateral dorsomedial globus pallidus and nearby regions in caudate, and right ventral striatum.

The time courses of the frontal, insula, and basal ganglia responses (Fig. $3 A, B$ ) were quite different than those for R TPJ. Low probability shift cues produced a time-locked response that was sometimes extended, but low probability stay cues and high probability shift cues evoked no activity. Therefore, these regions did not respond to unexpected cues that did not reorient attention, or to expected cues that evoked stimulus-driven shifts of attention. Rather, they mainly responded to unexpected cues that evoked a shift of attention. This interaction pattern was consistent with that expected for control regions that activate new attentional sets or inhibit competing processes (Fuster, 1989; Miller and Cohen, 2001). Anterior insula and anterior cingulate have been identified as the regions most consistently involved in cognitive control across a variety of tasks in human neuroimaging studies (Dosenbach et al., 2006).

A previous study demonstrated that greater activity in striatum was produced by infrequent than frequent randomly located peripheral stimuli that evoked shifts of attention (Zink et al., 2003), but did not test for an interaction of frequency and reorienting. Interestingly, this study manipulated expectation about temporal onset (i.e., infrequent stimuli were less expected), holding constant expectations about the spatial location of the peripheral stimulus. Here, the temporal predictability of cue onset was held constant across conditions (i.e., in all scans a cue appeared approximately every 2-6s) and expectations about spatial location were varied.

In addition to the basal ganglia/frontal/insula circuitry defined by the interaction of stimulus-driven reorienting and expectation signals, we were interested in evaluating R VFC, the frontal core of the putative ventral attention network. VFC includes a collection of regions in R anterior insula, R IFG, and R middle frontal gyrus, which tend to be variably recruited in different experiments (Corbetta and Shulman, 2002). Of these regions, only R IFG showed an interaction of cue probability and stimulus-driven reorienting (Fig. $3 A$ ), similar to the basal ganglia/frontal/insula regions discussed above, although the time course of BOLD activity was noisier. While activations were again mainly observed in the low probability shift cue condition, the transient and time-locked nature of the activation was less clear. However, the response in this region was quite different than that observed in R TPJ. The resting-state connectivity results presented below provide strong evidence that the present R IFG focus falls within the ventral network.

To summarize, basal ganglia and prefrontal/insula regions were only activated by stimulus-driven shifts of attention that were unexpected. Neither a breach of spatial expectation (i.e.,

\section{A. Cue Probability X Reorienting: Frontal/Insula Cortex}
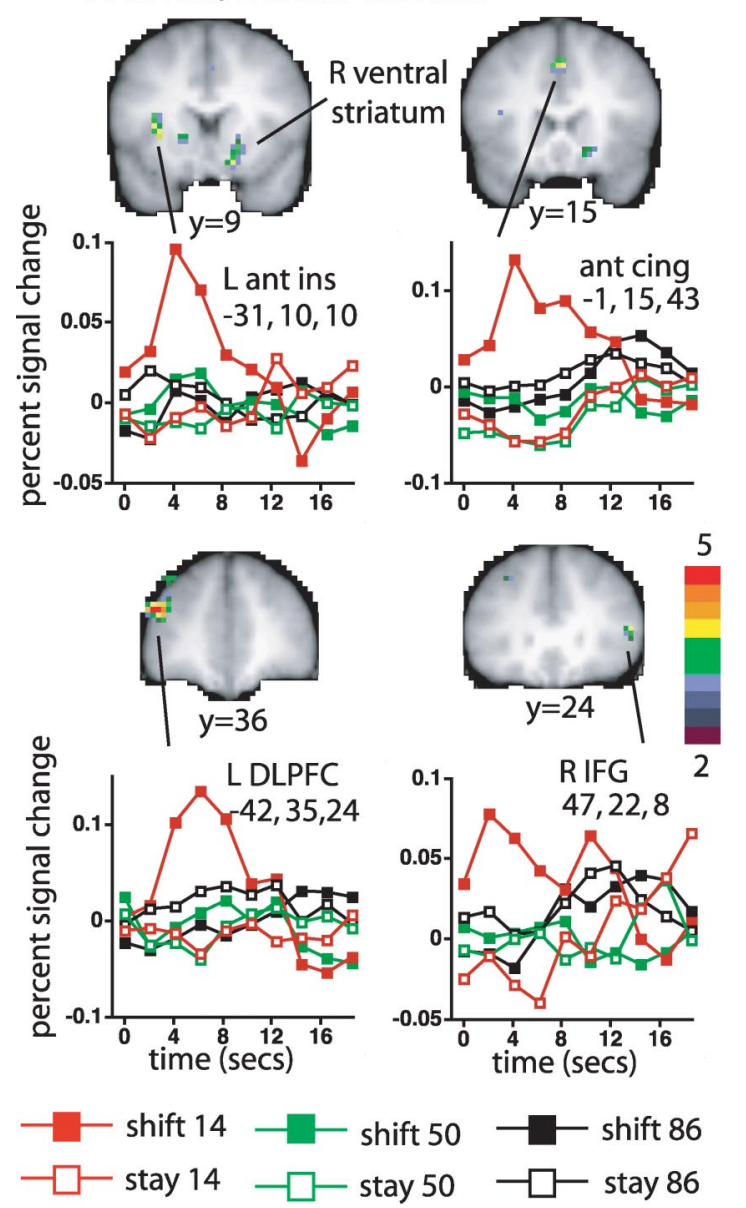

B. Cue Probability X Reorienting:

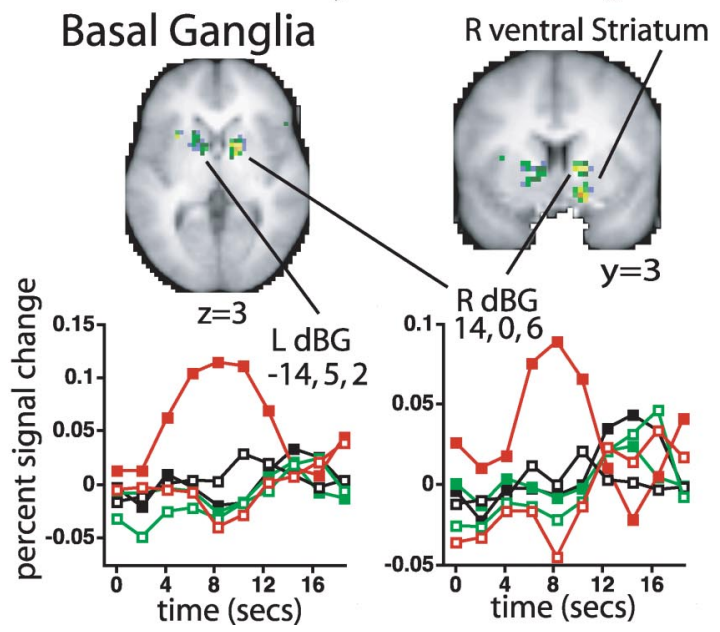

Figure 3. $\quad \boldsymbol{A}, \boldsymbol{B}$, Voxels in insula and frontal cortex $(\boldsymbol{A})$ and basal ganglia $(\boldsymbol{B})$ that showed a significant interaction of the shift versus stay effect with cue probability (transverse and coronal slices from the group cue type by cue probability by time ANOVA map, corrected for multiple comparisons). While the location of the most strongly activated voxels in the dorsal basal ganglia and the Talairach coordinates assigned to the dorsal activation foci by our automatic peakfinding procedure were most consistent with a globus pallidus assignment (Prodoehl et al., 2008), adjacent parts of the caudate were also activated, as shown in the slices. The color bar indicates the equivalent $z$-score for the $p$ value from the ANOVA. The graphs show the time course of the BOLD signal as a function of cue type and cue probability. Ant ins, Anterior insula; ant cing, anterior cingulate; $\mathrm{dBG}$, dorsal basal ganglia. 
Table 1. TPJ, SMG, prefrontal, anterior insula, and basal ganglia regions that showed significant differences between stay and shift cues in voxelwise statistical maps, corrected for multiple comparisons

\begin{tabular}{lllll}
\hline Region & $x$ & $y$ & $z$ & $z$-score \\
\hline Cue type (shift, stay) $\times$ time & & & & \\
R TPJ & 52 & -49 & 17 & 6.45 \\
R SMG & 51 & -45 & 32 & 5.60 \\
Anterior cingulate & -4 & 8 & 46 & 5.41 \\
& 4 & 18 & 37 & 3.17 \\
L anterior insula & -29 & 11 & 13 & 5.11 \\
L IFG & -31 & 47 & 14 & 3.89 \\
R IFG & 48 & 14 & 10 & 4.32 \\
& 36 & 17 & 16 & 3.66 \\
L DLPFC & -42 & 36 & 22 & 4.06 \\
& -33 & 32 & 31 & 5.02 \\
R DLPFC & 28 & 33 & 33 & 4.01 \\
& 30 & 42 & 23 & 3.96 \\
R basal ganglia & 13 & 4 & -6 & 3.71 \\
& 15 & -2 & 20 & 3.33 \\
Cue type (shift, stay) $\times$ cue probability & & & & \\
(0.14, 0.50, 0.86 ) $\times$ time & & & & \\
Anterior cingulate & -1 & 15 & 43 & 4.44 \\
L anterior insula & -31 & 10 & 10 & 4.12 \\
R IFG & 47 & 22 & 8 & 3.81 \\
L DLPFC & -42 & 35 & 24 & 5.21 \\
L dorsal basal ganglia & -31 & 32 & 42 & 3.77 \\
R dorsal basal ganglia & -14 & 5 & 2 & 3.89 \\
R ventral striatum & & 0 & 6 & 4.61 \\
\hline
\end{tabular}

spatial prediction error) nor reorienting alone was sufficient to activate these regions.

\section{Results for dorsal frontoparietal cortex}

Dorsal frontoparietal regions are thought to play a primary role in controlling attention (Corbetta et al., 1993, 2002; Nobre et al., 1997; Vandenberghe et al., 1997; Kastner et al., 1999; Hopfinger et al., 2000; Sylvester et al., 2007). We first identify two types of signals that were evoked by stimulus-driven reorienting, a transient signal that showed relatively weak spatial selectivity and a sustained signal that showed strong selectivity, and then examine how those signals for reorienting were affected by expectation.

Transient modulations due to reorienting in precuneus and parts of FEF/precentral

Large regions within dorsal frontoparietal cortex showed transient responses that differed for shift and stay cues, averaged over cue location, as indicated in Figure $4 A$, which shows the voxelwise cue type (shift, stay) by time ANOVA map. Parietal activations were observed most robustly in bilateral precuneus, extending into superior parietal lobule (SPL), and to a lesser degree in bilateral IPS extending into postcentral sulcus (Table 2). Significant dorsal frontal activations were observed most robustly in bilateral human FEF, extending laterally and ventrally in bilateral precentral sulcus, and in supplementary motor area (SMA). The graphs in Figure $4 A$, which show time courses for the four regions in dorsal frontoparietal cortex with the highest $z$-scores for the shift versus stay effect (Table 2), indicate the transient character of the bilateral precuneus/SPL and L FEF responses, which resembled a shift signal (Serences and Yantis, 2006a), as previously reported for these regions during symbolically directed shifts of attention (Yantis et al., 2002; Kelley et al., 2008).

Three of the four ROIs shown in Figure $4 A$ did not show significant spatial selectivity in regional ANOVAs, matching a previous report (Yantis et al., 2002). However, this result should be treated cautiously. Spatially selective signals have been reported in precuneus (Hagler et al., 2007; Jack et al., 2007; Sylvester et al., 2007; Saygin and Sereno, 2008) and both L FEF and L precuneus/SPL ROIs showed the expected trend for greater contralateral activity, a trend that was significant in a regional ANOVA on the R FEF ROI [cue type by cue location (left, right) by time $\left.\left(F_{(9,180)}=2.70, p=0.0095\right)\right]$. Spatially selective signals may be easier to image when the underlying neural processes are sustained (e.g., maintenance of attention) rather than transient (e.g., shifts of attention), as shown in the next section.

\section{Sustained, spatially selective modulations in IPS and parts of FEF/precentral}

Regions in IPS and parts of FEF/precentral sulcus showed sustained BOLD responses in which the difference between stay and shift cues significantly depended on whether the cue was contralateral or ipsilateral, as shown in Figure $4 B$ by the voxelwise ANOVA map for cue location (left, right) by cue type (shift, stay) by time (Table 2). Highly significant, spatially selective responses were also observed throughout occipital cortex (e.g., lateral view in Fig. $4 B$, supplemental Fig. 1, available at www.jneurosci.org as supplemental material). Because the ANOVA compared stay and shift cues that were presented at the same location, controlling for purely sensory activations, the activations reflected a spatially selective attentional modulation. Previous studies have reported spatial selectivity in these regions (Sereno et al., 2001; Schluppeck et al., 2005; Silver et al., 2005; Hagler and Sereno, 2006; Serences and Yantis, 2006b; Jack et al., 2007; Molenberghs et al., 2007; Swisher et al., 2007).

The time courses of the BOLD signal in dorsal IPS and FEF are shown in Figure $4 B$. Shift cues to a location produced a sustained increase in the contralateral hemisphere and a sustained decrease in the ipsilateral hemisphere that eventually returned to the level of activation produced by a stay cue, which showed smaller differences between ipsilateral and contralateral locations. The sustained decrease was not a true deactivation, however, since it did not occur relative to a resting baseline but only relative to a baseline that included both sensory-evoked and task-evoked activity; i.e., the important result was the difference between the ipsilateral and contralateral cue time courses. The sustained nature of the time courses likely reflected the maintenance of attention and/or the modulation of stimulus-evoked activity from the RSVP stream at the cued location.

While in parietal cortex there was a clear functionalanatomical segregation between the IPS regions that most strongly showed sustained signals and the precuneus regions that most strongly showed transient shift signals, the functionalanatomical segregation between the two types of signals in FEF/ precentral cortex was less clear and suggested some mixing of the two signal types (e.g., R FEF foci in Fig. 4, $A$ and $B$ ).

\section{Interaction of expectation and reorienting: regions showing transient signals}

We next consider how expectation affected reorienting in dorsal frontoparietal regions that showed transient shift signals. Figure $5 A$, which shows time courses for the four ROIs showing the largest shift versus stay $z$-scores, indicates that activations were greater for low probability than middle or high probability cues. The latter two conditions showed similar activation magnitudes, again indicating that the effect of cue probability was best described as a breach of expectation. Importantly, however, the probability effect was largely confined to shift cues, with weak or 


\section{A. Dorsal fronto-parietal cortex: effects of reorienting}
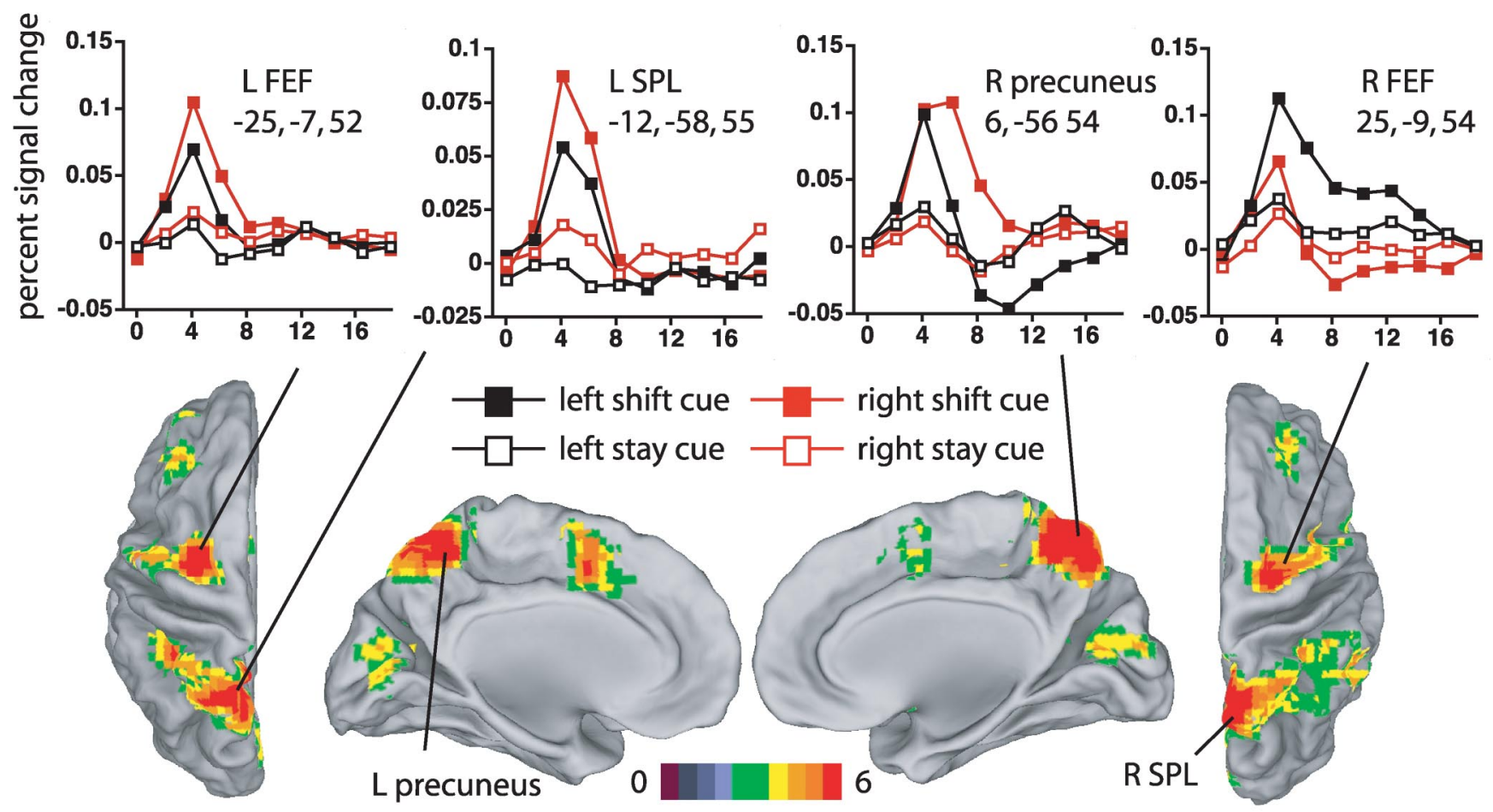

\section{B. Dorsal fronto-parietal cortex: spatially selective effects of reorienting}
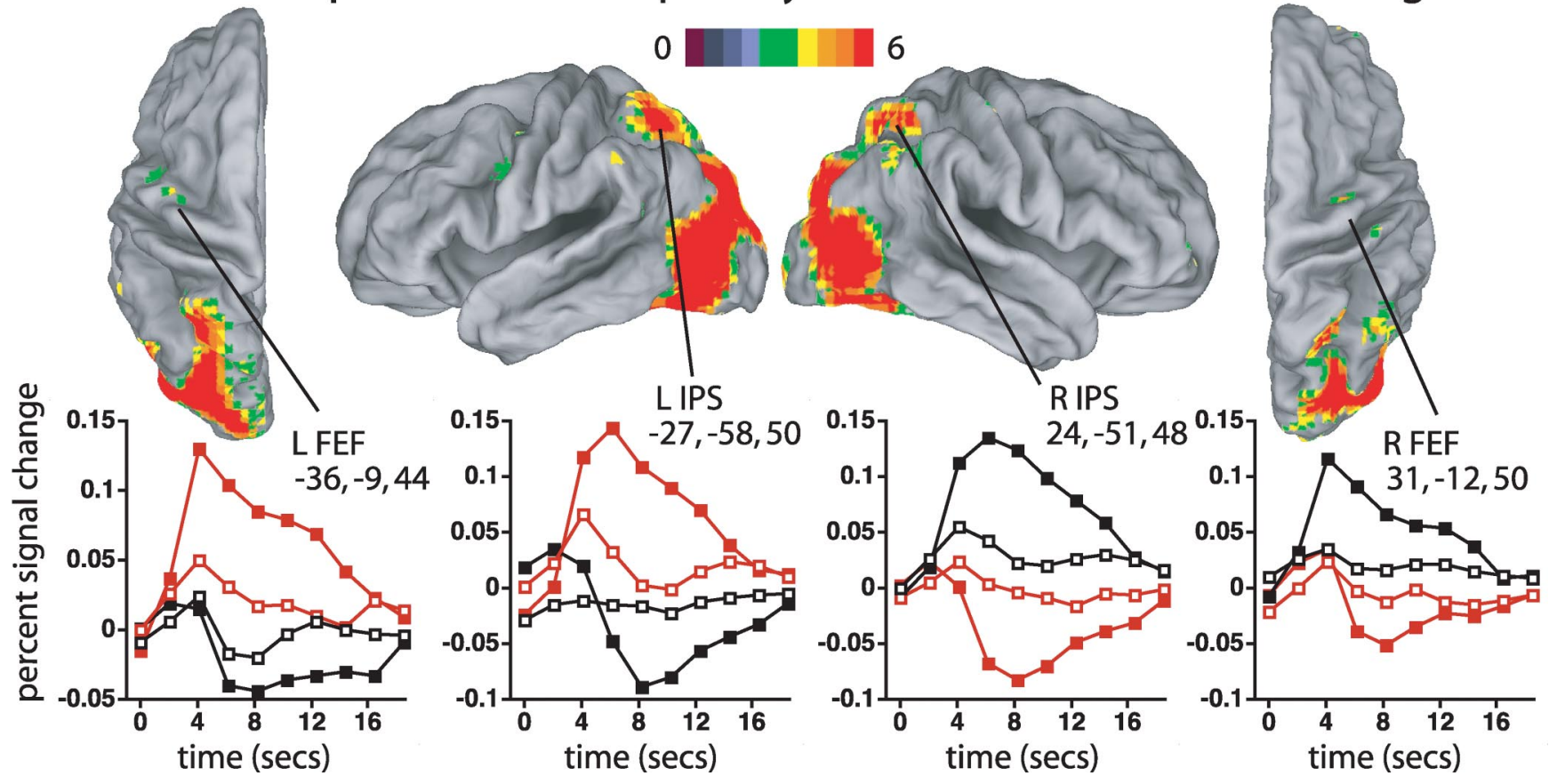

Figure 4. A, Dorsal and medial views of voxels that showed significantly different activations following shift and stay cues (cue type by time ANOVA map, corrected for multiple comparisons). The graphs show the time course of the BOLD signal as a function of cuetype and cue location. The color bar indicates the equivalent $Z$-score for the $p$ value from the ANOVA. $\boldsymbol{B}$, Dorsal and lateral views of voxels in which the difference between shift and stay cues significantly depended on the location of the cue (cue location by cue type by time, corrected for multiple comparisons).

absent effects for stay cues, unlike the additive effects of probability and reorienting observed in R TPJ.

The interaction of reorienting and expectation was significant in both of the medial parietal regions showing transient spatially nonselective shift signals, i.e., $\mathrm{R}$ precuneus $\left(6,-56,54, F_{(18,360)}=\right.$ $2.17, p=0.01)$ and $\mathrm{L}$ precuneus/SPL $\left(-12,-58,55, F_{(18,360)}=\right.$
$2.29, p=0.006)$, and was marginally significant in R FEF $(25,-9$, $\left.54, F_{(18,360)}=1.81, p=0.039\right)$. These regional analyses were corroborated by voxelwise results shown in supplemental Figure 2 (available at www.jneurosci.org as supplemental material) and Table 2. Finally, the same two medial parietal ROIs that showed a significantly greater effect of shifting attention when cues were 


\begin{tabular}{|c|c|c|c|c|}
\hline Region & $x$ & $y$ & $z$ & z-score \\
\hline \multicolumn{5}{|c|}{ Cue type (shift, stay) $\times$ time } \\
\hline L precuneus/SPL & -12 & -58 & 55 & 7.19 \\
\hline LSPL & -15 & -69 & 46 & 5.25 \\
\hline Rprecuneus & 6 & -56 & 54 & 7.44 \\
\hline R SPL/Precuneus & 6 & -71 & 56 & 4.11 \\
\hline Lant IPS & -33 & -46 & 57 & 4.50 \\
\hline LIPS & -28 & -54 & 44 & 4.60 \\
\hline \multirow[t]{3}{*}{ RIPS } & 27 & -48 & 61 & 4.84 \\
\hline & 33 & -56 & 52 & 3.94 \\
\hline & 21 & -62 & 39 & 3.59 \\
\hline L postcentral & -35 & -41 & 43 & 6.03 \\
\hline R dorsal SMG & 37 & -41 & 49 & 4.59 \\
\hline R dorsal SMG & 42 & -57 & 43 & 3.64 \\
\hline LFEF & -25 & -7 & 52 & 7.30 \\
\hline RFEF & 25 & -9 & 54 & 6.96 \\
\hline \multirow[t]{2}{*}{ L precentral } & -48 & -4 & 39 & 5.02 \\
\hline & -36 & 2 & 32 & 3.23 \\
\hline R precentral & 43 & 2 & 40 & 4.91 \\
\hline SMA & -1 & 0 & 56 & 4.76 \\
\hline \multicolumn{5}{|c|}{ Cue type (shift, stay) $\times$ cue location (left, right) $\times$ time } \\
\hline LSPL & -7 & -71 & 52 & 3.82 \\
\hline LSPL/IPS & -16 & -80 & 42 & 5.59 \\
\hline LIPS & -27 & -58 & 50 & 7.59 \\
\hline L ventral IPS & -25 & -75 & 30 & 8.75 \\
\hline RSPL/IPS & 15 & -85 & 39 & 5.08 \\
\hline RIPS & 24 & -51 & 48 & 8.78 \\
\hline R ventral IPS & 26 & -82 & 32 & 7.38 \\
\hline L ventral precentral & -41 & 2 & 33 & 4.12 \\
\hline L Precentral & -49 & -4 & 52 & 4.66 \\
\hline LFEF & -36 & -9 & 44 & 4.13 \\
\hline RFEF & 31 & -12 & 51 & 4.78 \\
\hline \multicolumn{5}{|c|}{ Cue type (shift, stay) $\times$ cue probability $(0.14,0.50,0.86) \times$ time } \\
\hline LSPL & -7 & -69 & 53 & 5.31 \\
\hline RSPL & 11 & -67 & 57 & 5.22 \\
\hline Lant IPS & -30 & -49 & 40 & 4.74 \\
\hline L precuneus & -4 & -57 & 49 & 4.15 \\
\hline RFEF & 22 & -9 & 61 & 4.49 \\
\hline R FEF & 39 & -14 & 48 & 4.38 \\
\hline
\end{tabular}

ant, Anterior.

unexpected, nevertheless showed highly significant shift versus stay differences in regional analyses when only expected (high probability) cues were analyzed (L precuneus/SPL: $-12,-58,55$ : $F_{(9,180)}=4.99, p<0.0001$; R precuneus: $06,-56,54: F_{(9,180)}=$ $4.15, p<0.0001$ ) (see supplemental Figs. 2, 3, available at www. jneurosci.org as supplemental material, for corresponding effects in the voxelwise maps).

Interaction of expectation and reorienting: regions showing sustained, spatially selective signals

Figure $5 B$ shows the effect of expectation on the time course of activation following a shift cue in the four dorsal frontoparietal regions from Figure $4 B$ that showed sustained, spatially selective differences between stay and shift cues. Low probability shift cues increased the activation from both ipsilateral and contralateral cues, resulting in an effect of cue probability that was largely independent of spatial location and therefore did not enhance the spatial selectivity of the activation. While breaches of expectation produced overall increases in the BOLD signal, the interaction of expectation and reorienting was less robust. Regional ANOVAs on the four ROIs yielded a marginally significant cue type by cue probability by time interaction in one parietal region, L IPS $\left(-27,-58,50, F_{(18,360)}=1.83, p=0.036\right)$ and in $\operatorname{R~FEF~}\left(31,-12,51, F_{(18,360)}=1.74, p=0.049\right)$, indicating that in some ROIs the probability effect modestly differed for stay and shift cues. The weaker nature of the effects of expectation on reorienting was also evident in the corresponding voxelwise statistical map (supplemental Fig. 2, available at www.jneurosci.org as supplemental material), which was not significant in IPS.

To summarize, in dorsal frontoparietal regions, breaches of expectations enhanced signals due to reorienting. This effect was more pronounced in medial parietal (precuneus) regions showing transient signals to the cue than in more lateral parietal regions (IPS) showing sustained spatially selective signals, possibly reflecting different functional roles of these regions in shifting and maintaining attention, respectively. As with the basal ganglia/frontal/insula regions discussed above, interacting effects of expectation and reorienting cannot be ascribed to a general increase in arousal when an expectation is breached, but indicate a specific effect of expectation on shifts of attention. However, unlike basal ganglia/frontal/insula regions, dorsal frontoparietal regions showed highly significant differences between stay and shift cues even when those cues were expected, consistent with the primary role of the dorsal network in shifting attention.

\section{Interaction of expectation and reorienting across networks}

The preceding analyses have indicated that R TPJ, basal ganglia/ frontal/insula regions and dorsal frontoparietal shift regions fall 


\section{A. Dorsal fronto-parietal cortex: effects of cue probability in 'shift' regions}
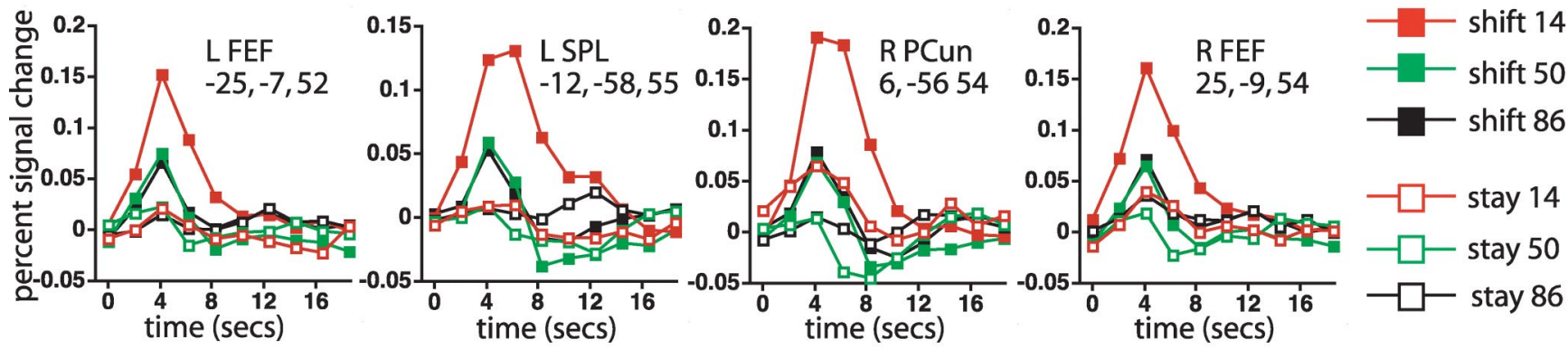

\section{B. Dorsal fronto-parietal cortex: effects of cue probability in spatially-selective regions}
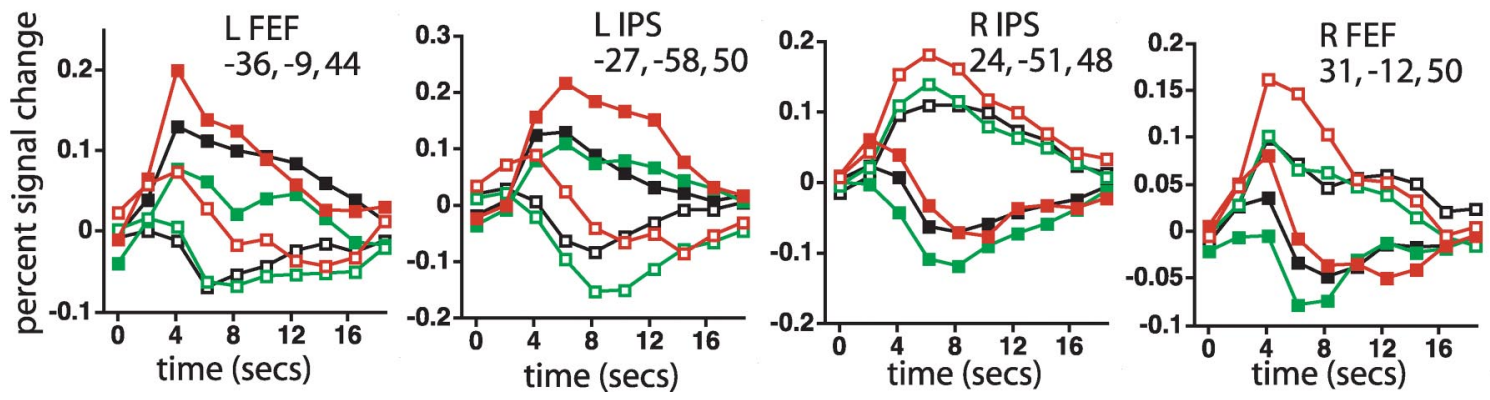

shift cues only

Figure 5. A, The graphs show the time course of the BOLD signal as a function of cue type and cue probability in ROls defined from the cue type by time map, corrected for multiple comparisons. $\boldsymbol{B}$, The graphs show the time course of the BOLD signal for shift cues only as a function of cue probability and cue location in ROls defined by the cue type by cue location by time map, corrected for multiple comparisons. PCun, Precuneus.

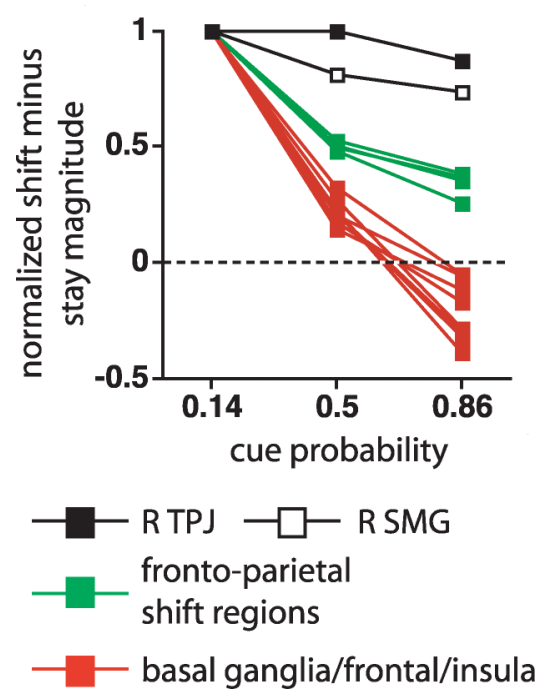

Figure 6. The graphs display the shift cue minus stay cue magnitude at three probability levels, normalized by the magnitude at the 0.14 probability level. Each line in the graph corresponds to a different ROI. The R TPJ and R SMG ROIs are taken from the multiple-comparison corrected cue type by time ANOVA map. The frontoparietal shift ROls are the four foci that showed the largest $z$-scores in the multiple-comparison corrected cue type by time map (Table 2 ), and the eight basal ganglia/frontal/insula ROIs are from the multiple-comparison corrected cue type by cue probability by time map (Table 1).

along different points on a continuum that reflects the effect of expectation on reorienting. TPJ falls on one end of the continuum with equivalent shift versus stay activations under high and low probability conditions, the most robust dorsal frontoparietal shift regions fall in the middle, with shift versus stay activations that are present under high probability conditions but are increased under low probability conditions, and basal-ganglia/ frontal/insula regions and R IFG fall on the other end, with shift versus stay activations only under low probability conditions.

We illustrate this point using a metric that allows the different regions to be more readily compared. The graph in Figure 6 displays a shift minus stay magnitude for each probability level, normalized by the magnitude at the 0.14 probability level, where a single line in the graph displays the magnitudes from a single region. Magnitudes were computed from the observed time courses using a standard hemodynamic response function (Boynton et al., 1996). Figure 6 shows the normalized magnitudes for TPJ and SMG (from the cue type by time map; Table 1, Fig. 2), the four dorsal frontoparietal regions that showed the largest $z$-scores for the difference between shift and stay cues (from the cue type by time map; Table 2, Fig. $4 A$ ), and the eight IFG, frontal/insula, and basal ganglia regions from the voxelwise map for the interaction of cue type by cue probability by time (Table 1, Fig. 3 ). The distribution of the three region sets corresponded to the description above, with TPJ/SMG and basal ganglia/frontal/insula regions on the extremes and dorsal frontoparietal shift regions in the middle.

At the level of individual subjects, the normalized magnitude measure was very unstable and sensitive to noise since some subjects had small magnitudes in the denominator. Therefore, we used the nonparametric Mann-Whitney $U$ test to compare the group-averaged distributions between region sets at the 0.86 probability level normalized values, which by hypothesis should most strongly differentiate the three region sets. Significant differences were found between dorsal frontoparietal cortex and basal ganglia/frontal/insula cortex $\left(U=0, U^{\prime}=32 ; p=0.007\right)$ 
and basal ganglia/frontal/insula versus TPJ/ $\operatorname{SMG}\left(U=0, U^{\prime}=16, p=0.037\right)$. The difference between dorsal frontoparietal cortex versus TPJ/SMG was marginal $\left(U=0, U^{\prime}=\right.$ $8 ; p=0.064)$, entirely because of the small number of regions involved $(n=6)$. However, each of the 24 dorsal frontoparietal ROIs listed in Table 2 from the cue type by time and cue type by cue probability by time voxelwise maps had a value for the normalized 0.86 shift versus stay magnitude that was less than that for either R SMG or R TPJ.

\section{Resting-state functional connectivity}

The task activation analyses indicated that three sets of brain regions were differentially modulated by reorienting and expectation. To determine if these regions formed coherent networks, we measured resting-state functional connectivity (rsfcMRI), using the task-evoked foci as seeds, in an independent set of subjects $(n=11)$.

\section{Basal ganglia/frontal/insula}

Figure $7 A$ shows the rs-fcMRI maps that used as seeds the dorsal basal ganglia ROIs from the cue type by cue probability by time interaction. A striking pattern of selective rs-fcMRI was observed with the task-evoked frontal/insula ROIs in anterior cingulate, $\mathrm{L}$ anterior insula, and $\mathrm{L}$ DLPFC that also showed the cue type by cue probability by time interaction (indicated in Fig. $7 A$ by the white circles). Supplemental Figure 4 (available at www. jneurosci.org as supplemental material) shows that strong inter-regional rs-fcMRI was obtained between the cortical regions of this network, namely L DLPFC (the more inferior focus), anterior cingulate, and $\mathrm{L}$ anterior insula. These observations from the voxelwise maps were confirmed with pairwise regional statistical analyses (see supplemental text, available at www.jneurosci.org as supplemental material, for detailed statistics). As summarized in Table 3, rs-fcMRI for all of the ROI-ROI pairs within the basal ganglia/frontal/insula network exceeded the $p<0.01$ significance threshold, except for a single pair with $p<0.05$.

In summary, a robust basal-ganglia/frontal/insula resting-state network was observed in regions that were only activated by unexpected cues to shift attention. Interactions between human basal ganglia and frontal and insula cortex (Postuma and Dagher, 2006; Di Martino et al., 2008) are thought to be consistent with the principle of parallel corticostriatal loops (Alexander et al., 1986; Alexander and Crutcher, 1990), although the disparate frontal/insula regions of the current network may not be subsumed within a single loop.

\section{$R T P J / I F G$}

Previous reports have indicated that R IFG and R TPJ show strong functional connectivity (Fox et al., 2006; He et al., 2007), supporting the hypothesis of a ventral attention network. While in the present study R IFG and R TPJ showed different activation patterns, they nonetheless showed strong and selective rs-fcMRI
B. TPJ $<->$ IFG

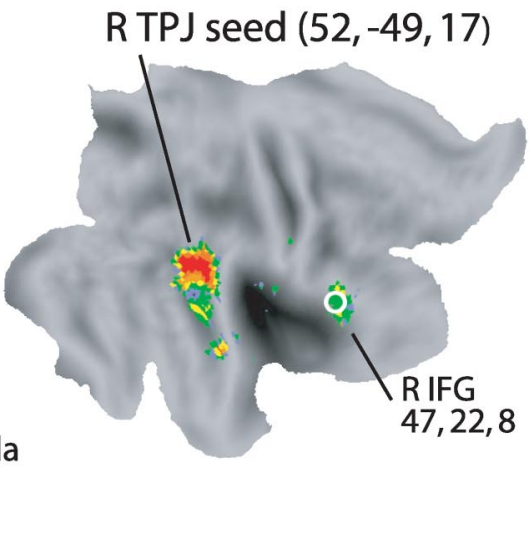

R IFG seed $(47,22,8)$

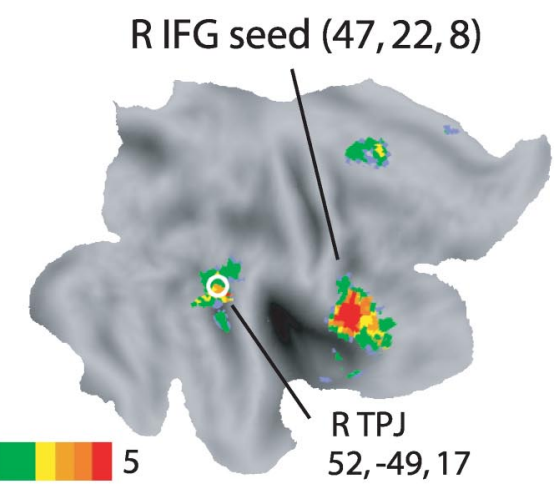

2

$-31,10,10$

Figure 7. $\quad \boldsymbol{A}$, Flat-maps of voxelwise rs-fcMRI statistical maps in a separate group of subjects $(n=11)$ using as seeds the left and right dorsal basal ganglia ROIs that showed a significant interaction of cue type by cue probability by time, corrected for multiple comparisons. The group voxelwise z-map is shown for a 1-sample, random effects $t$ test, corrected for multiple compar(he scans involving the RSV task. $\boldsymbol{B}$, Flat-maps of voxelwise rs-fcMRI between R TPJ and R IFG. The group for multiple comparisons), while in the bottom map, the seed was centered at the significant RIFG focus from the interaction map (i.e., cue type by cue probability by time, corrected for multiple comparisons) for the RSVP task.

in voxelwise maps that used each focus as a seed (Fig. 7B). A regional analysis confirmed highly significant rs-fcMRI between the two regions $\left(t_{(10)}=6.44, p<0.0001\right)$.

Basal-ganglia/frontal/insula versus $R$ TPJ/IFG

When all possible ROI pairings between the basal-ganglia/frontal/insula and R TPJ/IFG networks were averaged, the overall rs-fcMRI between networks was not significant $\left(t_{(10)}=1.67, p>\right.$ 0.1 ) (Fig. 8) (see Table 3 and supplemental Text, available at www.jneurosci.org as supplemental material, for regional statistics on pairwise comparisons). Therefore, although both networks were recruited when subjects shifted attention to an unexpected stimulus, they showed at best modest interactions in the resting state.

Dorsal frontoparietal regions versus basal ganglia/frontal/insula and $R$ TPJ/IFG networks

Because of the primary role of the dorsal network in controlling attention and because dorsal activations for shifts of attention were enhanced when those shifts were unexpected, we measured the resting correlation of the dorsal network with the basal gan- 
Table 3. $p$ values of resting-state $\mathrm{fcMRI}$ between indicated regions

\begin{tabular}{|c|c|c|c|c|c|c|c|}
\hline & $\mathrm{LdBG}$ & $\mathrm{RdBG}$ & ant cing & Lant ins & LDLPFC & RIFG & R TPJ \\
\hline $\mathrm{LdBG}$ & & +++ & +++ & + & ++ & -- & -- \\
\hline $\mathrm{RdBG}$ & & & +++ & ++ & +++ & - & -- \\
\hline ant cing & & & & +++ & +++ & + & -- \\
\hline L ant ins & & & & & +++ & + & -- \\
\hline LDLPFC & & & & & & -- & -- \\
\hline RIFG & & & & & & & +++ \\
\hline RTPJ & & & & & & & \\
\hline
\end{tabular}

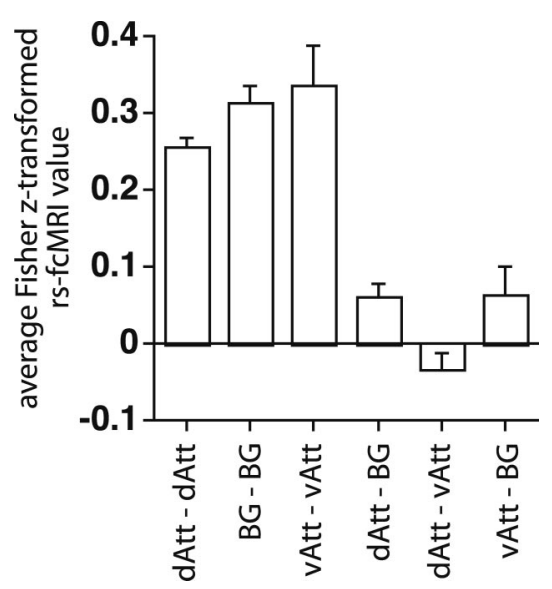

Figure 8. The graph shows the group-averaged Fisher z-transformed value for all ROI pairs within a network for three different networks, or for all ROI pairs between networks. Error bars are computed over the 11 subjects. $\mathrm{dAtt}$, The dorsal attention network, comprising 35 regions (see Table 2 for all foci): 18 foci that showed a shift versus stay difference (from the cue type by time map, corrected for multiple comparisons), 11 foci that showed a shift versus stay difference that depended on cue location (from the cue type by cue location by time map, corrected for multiple comparisons), and six foci that showed a shift versus stay difference that depended on cue probability (from the cue type by cue probability by time map, corrected for multiple comparisons). BG, The basal ganglia/frontal/insula network, comprising five regions: $L$ and $R$ dorsal basal ganglia, anterior cingulate, L DLPFC, and L anterior insula. vAtt, The ventral attention network, comprising R TPJ and R IFG.

glia/frontal/insula and TPJ/IFG networks recruited by unexpected shifts of attention. Average connectivity scores were computed within and between networks (Fig. 8). Modest but significant overall positive rs-fcMRI was observed between the basal ganglia/frontal/insula network and dorsal frontoparietal regions $\left(t_{(10)}=3.39, p=0.007\right)$. Pairwise regional analyses indicated that dorsal frontoparietal rs-fcMRI with the basal ganglia/ frontal/insula network was strong through L DLPFC $\left(t_{(10)}=\right.$ 6.86, $p<0.0001$; see supplemental Fig. 4, available at www. jneurosci.org as supplemental material) and to a lesser extent L anterior insula $\left(t_{(10)}=4.06, p=0.0023\right)$. Significant connectivity of DLPFC with posterior parietal cortex is consistent with previous anatomical studies in monkeys (Goldman-Rakic, 1988) and functional connectivity studies in humans (Seeley et al., 2007).

In contrast, no significant overall rs-fcMRI was observed between $\mathrm{R}$ TPJ-IFG and dorsal frontal-parietal regions $\left.t_{(10)}=-1.65, p>0.1\right)$. While this null result could indicate that these regions did not interact during task states, it could also indicate the highly contingent nature of those interactions. We have previously argued that the resting-state independence of $\mathrm{R}$ TPJ from both dorsal frontoparietal and default networks allows TPJ to flexibly switch between those networks during task states (Corbetta et al., 2008).

\section{Eye movement recording}

Two summary measures were applied to the eye movement data for each subject. First, the mean eye position during periods in which the left RSVP stream was attended was compared with the mean eye position during periods in which the right RSVP stream was attended, indicating whether there was any overall bias to fixate nearer the attended stream. Second, the mean changes in eye position evoked by stay and shift cues were measured, indicating whether eye movements affected event-related BOLD responses to the cues. To compute the second measure, the mean eye position during the 0 to $100 \mathrm{~ms}$ period following cue onset was used as a baseline while the mean eye position in the 1750 to $2000 \mathrm{~ms}$ period following cue onset was used to assess movements. Measures in other time periods (e.g., from 550 to $775 \mathrm{~ms}$ or from 775 to $1000 \mathrm{~ms}$ ) yielded similar results. Both measures identified two subjects who made excessive movements. For one subject, the mean difference in eye position when the left and right streams were attended was $-6.2 \mathrm{deg}$ (where negative numbers refer to a leftward shift), while the mean change in eye position following left and right shift cues was, respectively, -5.3 and $6.5 \mathrm{deg}$ (where negative numbers refer to leftward shifts). For the other subject, the analogous measures were $-2.0,-2.4$, and 2.0 deg. The data from these two subjects were not included in the results reported above.

For the remaining subjects, the mean difference in eye position when attending to the left and right streams was $-0.11 \mathrm{deg}$. The mean change in eye position following left and right field shift cues was $-0.17 \mathrm{deg}$. and $0.10 \mathrm{deg}$. respectively. These small deviations in eye position from fixation indicate that subjects largely followed instructions. In addition to the quantitative data given above, each subjects' eyes were carefully monitored via a camera on all scans regardless of whether eye movement records were also collected.

Finally, our results cannot be explained by eye movements. The regions in TPJ, frontal cortex, insula, and the associative division of the basal ganglia, which provided many of the primary results of the present study, are not classically involved in the control of eye movements. Dorsal frontoparietal regions do show eye movement responses, but the effects of expectation on reorienting in these regions were actually intermediate between those for TPJ on the one hand and basal ganglia/frontal/insula cortex on the other. Moreover, dorsal parietal regions, as well as occipital regions, showed strong spatially selective attentional activations, which would not have occurred if subjects moved their eyes and fixated the attended stream, and the spatial selectivity of the activations was independent of expectation. Finally, it is unlikely that eye movements occurred during the resting-state scans, in which no peripheral stimuli were presented and the subject's only task was to remain fixated. Yet there was a striking correspondence between the TPJ-IFG and basal ganglia/frontal/insula net- 
works identified from the resting-state scans and the regions identified from the scans involving the RSVP task.

\section{Discussion}

Previous work showed that right TPJ and VFC were activated by stimulus-driven reorienting to unexpected stimuli, forming a putative ventral attention network, but did not separately measure effects of reorienting and expectation or identify different functions for these regions (Corbetta and Shulman, 2002). The current results addressed both issues.

\section{Ventral attention network: reorienting and expectation}

R TPJ showed a significant difference between stay and shift cues even when they were expected, and this difference was not increased when cues were unexpected and did not depend on visual field. These results suggest that TPJ functioned during stimulusdriven reorienting as a switch or resetting mechanism that was activated in a similar manner regardless of the characteristics of the attentional shift. TPJ activity may facilitate transitions of networks between states associated with different environmental stimuli (Corbetta et al., 2008), extending an earlier proposal that TPJ activity (Friedrich et al., 1998) during reorienting "disengaged" attention (Posner et al., 1984) from the current focus. Additionally, a breach of expectation separately activated TPJ, indicating the critical importance of controlling expectancy effects when studying TPJ. This independent breach of expectation signal may not occur in the same TPJ neurons and/or with the same latency as the reorienting signal.

Both reorienting and expectation signals were consistent with the recent hypothesis that BOLD TPJ activity relates to singleunit activity in the locus ceruleus/norepinephrine (LC/NE) system (Corbetta et al., 2008). The LC/NE system has long been related to changes in arousal (Aston-Jones and Bloom, 1981a,b), a likely consequence of an unexpected event, and the putative role of TPJ in reorienting is similar to recent proposals that LC/NE activity promotes the reorganization of neural networks when a behaviorally important stimulus is detected (Aston-Jones and Cohen, 2005; Bouret and Sara, 2005).

The independence of reorienting and expectation signals strongly dissociated TPJ from the second main component of the ventral attention network, R IFG, which was activated by stimulus-driven reorienting only when reorienting was unexpected. One clue to R IFG function was the relatively weak activation in the present study, in which no motor response was made to the cue, compared with previous studies that imaged activations to invalid and oddball targets, which involved motor responses. In these latter studies, R IFG activity may have inhibited a prepared response when an unexpected target appeared that potentially required a different course of action (Nobre et al., 1999; Arrington et al., 2000), consistent with the well documented role of R IFG in response inhibition (Aron et al., 2004a) (but see Hampshire et al., 2007).

If R IFG activity inhibits prepared motor responses, why was activity, although weak, observed for an unexpected shift cue not associated with a response? We suggest response-related inhibition may be proactive as well as reactive, i.e., when responses are held in readiness for a target, some inhibition may be generated whenever attention is shifted to an unexpected object. Second, R IFG inhibitory functions may not be purely response-related (Aron et al., 2004a). R TPJ-R IFG coactivation may facilitate termination of ongoing activity and disengagement of attention when shift cues are unexpected.

Both putative inhibitory functions of R IFG activity would lead to strong TPJ-IFG resting-state functional connectivity, since TPJ-IFG coactivation would occur under the ecological conditions in which stimulus-driven reorienting is typically evoked.

\section{A distinct basal ganglia/frontal/insula network}

The ventral attention network was distinguished under resting conditions from a second network, comprising bilateral dorsal basal ganglia, anterior cingulate, L DLPFC, and L anterior insula, which was recruited by stimulus-driven shifts of attention only when unexpected. Ventral attention and basal-ganglia/frontal/ insula networks may principally involve different neuromodulators, norepinephrine and dopamine, respectively.

Surprisingly, neuroimaging studies of the Posner task, in which a cue indicates the likely location of a subsequent target, have not reported greater basal ganglia activations to targets that occurred in spatially uncued (invalid) than cued (valid) locations (Arrington et al., 2000; Corbetta et al., 2002; Macaluso et al., 2002; Thiel et al., 2004; Kincade et al., 2005; Giessing et al., 2006), although invalid targets are unexpected, behaviorally relevant, and evoke shifts of attention, while valid targets are expected and do not evoke attentional shifts. Invalid targets in Posner paradigms involving temporal cueing also are not reported to activate basal ganglia (Coull et al., 2000). These null neuroimaging results should be treated very cautiously and may reflect methodological factors, but raise the possibility that the strength of the relationship between breaches of expectation (prediction errors), shifts of attention, and basal ganglia activity depends on the context in which prediction errors/shifts occur, as discussed below.

Animal studies have divided basal ganglia into motor, associative, and limbic divisions (Alexander et al., 1986; Parent and Hazrati, 1995; Middleton and Strick, 2002). The motor division includes a separate oculomotor circuit (Hikosaka and Wurtz, 1983; Hikosaka et al., 1989) that might plausibly be involved in stimulus-driven reorienting (Boussaoud and Kermadi, 1997), particularly given the overlapping brain regions involved in overt and covert orienting (Corbetta et al., 1998). However, the anatomical locations of the most activated basal ganglia region (dorsomedial pallidus) and functionally connected DLPFC/cingulate/insula regions were more consistent with associative than oculomotor pathways. The absence of activity during shifts of attention to middle- or high-probability cues, indicating a predominant influence of cognitive variables, also suggests that basal ganglia activations reflected functions of the associative rather than oculomotor divisions.

The associative division includes lateral prefrontal/basal ganglia circuits (Alexander et al., 1986) that have been implicated in switching between attentional sets (Downes et al., 1993; Owen et al., 1993; Hayes et al., 1998; Monchi et al., 2001; Cools et al., 2004, 2006). In switching paradigms, a previously irrelevant stimulus/ feature is selected to control a behavioral response, updating task-related information in working memory. We suggest that an unexpected stimulus to shift attention evoked a similar updating process. Retrieval/activation in working memory of commands to shift attention (Goldman-Rakic, 1995; Frank et al., 2001; Lewis et al., 2004; Cools et al., 2008; McNab and Klingberg, 2008) may enable unexpected attentional shifts to be implemented by dorsal frontoparietal regions, perhaps through interactions with L DLPFC (Aron et al., 2004b; Mayr et al., 2006), which showed robust rs-fcMRI with the dorsal network.

The above account leaves open the possibility that basal ganglia/frontal/insula activations during unexpected shifts of attention are more robust in the present than Posner tasks. Before an 
unexpected shift of attention, subjects had not recently shifted attention (present task), rather than just previously on the same trial (Posner), and had been continuously engaged in a demanding monitoring task at the attended location (present task), rather than simply waiting for target onset (Posner). Both features of the present paradigm may have increased the extent to which commands for shifting attention were inactive before an unexpected shift stimulus and had to be retrieved/activated.

Switching and spatial attention paradigms have important differences. In task switching paradigms, for example, one of several stimulus-response mappings is executed based on the context provided by other stimuli or instructions, while in spatial attention paradigms shifts of attention are executed that are largely context independent (Hayes et al., 1998). Here, the cue was always a distinctive red square and was always attended. However, frontostriatal circuits may underlie both contextdependent selection of stimulus-action pairings and selection of less context-dependent but unexpected stimulus-action pairings (peripheral red square- $>$ shift attention). Importantly, this putative function of basal ganglia-frontal activity during stimulusdriven reorienting was not exercised routinely, unlike R TPJ, whose activity was closely coupled to reorienting.

\section{The primary role of dorsal frontoparietal cortex in orienting}

During stimulus-driven reorienting to task-relevant objects, TPJ is coactivated with dorsal frontoparietal regions [see present study and the studies of Corbetta et al. (2002) and Giessing et al. (2006)]. However, when attention is shifted endogenously, only dorsal frontoparietal regions are activated (Corbetta and Shulman, 2002), indicating their primary role in controlling spatial attention. The precuneus, activated here by stimulus-driven reorienting, is also activated by shifts of attention instructed by symbolic cues at the currently attended location (Yantis et al., 2002).

A clear functional-anatomical segregation was observed between these precuneus shift regions (Serences and Yantis, 2006a) and IPS regions that showed sustained spatially selective signals (Serences and Yantis, 2006b), suggesting complementary roles in shifting and maintaining attention [see Kelley et al. (2008) and Molenberghs et al. (2007) for other dissociations]. Shift regions may enable spatially selective sustained regions, which maintain biasing signals in occipital cortex.

Activity in dorsal frontoparietal shift regions was selectively increased by unexpected shifts of attention, likely reflecting not only increased local activity that specified the parameters of the attentional shift, but also increased interactions with prefrontal regions such as L DLPFC (Goldman-Rakic, 1988; Seeley et al., 2007), which showed significant rs-fcMRI with the dorsal network. Overall, the results in dorsal frontoparietal regions, i.e., the significant activity observed for expected shifts of attention, the increase in that activity for unexpected shifts, and the presence of spatially selective modulations, indicated a primary role in shifting spatial attention. The dorsal network, however, was augmented by the ventral network when shifts of attention were stimulus-driven and by the basal-ganglia/frontal/insula network when infrequent stimulus-driven shifts of attention occurred within a demanding ongoing task.

\section{References}

Alexander GE, Crutcher MD (1990) Functional architecture of basal ganglia circuits: neural substrates of parallel processing. Trends Neurosci 13:266-271.

Alexander GE, DeLong MR, Strick PL (1986) Parallel organization of func- tionally segregated circuits linking basal ganglia and cortex. Ann Rev Neurosci 9:357-381.

Aron AR, Robbins TW, Poldrack RA (2004a) Inhibition and the right inferior frontal cortex. Trends Cogn Sci 8:170-177.

Aron AR, Monsell S, Sahakian BJ, Robbins TW (2004b) A componential analysis of task-switching deficits associated with lesions of left and right frontal cortex. Brain 127:1561-1573.

Arrington CM, Carr TH, Mayer AR, Rao SM (2000) Neural mechanisms of visual attention: object-based selection of a region in space. J Cogn Neurosci 12:106-117.

Aston-Jones G, Bloom FE (1981a) Nonrepinephrine-containing locus coeruleus neurons in behaving rats exhibit pronounced responses to nonnoxious environmental stimuli. J Neurosci 1:887-900.

Aston-Jones G, Bloom FE (1981b) Activity of norepinephrine-containing locus coeruleus neurons in behaving rats anticipates fluctuations in the sleep-waking cycle. J Neurosci 1:876-886.

Aston-Jones G, Cohen JD (2005) An integrative theory of locus coeruleusnorepinephrine function: adaptive gain and optimal performance. Annu Rev Neurosci 28:403-450.

Bisley JW, Goldberg ME (2003) Neuronal activity in the lateral intraparietal area and spatial attention. Science 299:81-86.

Bouret S, Sara SJ (2005) Network reset: a simplified overarching theory of locus coeruleus noradrenaline function. Trends Neurosci 28:574-582.

Boussaoud D, Kermadi I (1997) The primate striatum: neuronal activity in relation to spatial attention versus motor preparation. Eur J Neurosci 9:2152-2168.

Boynton GM, Engel SA, Glover GH, Heeger DJ (1996) Linear systems analysis of functional magnetic resonance imaging in human V1. J Neurosci $16: 4207-4221$

Brainard DH (1997) The psychophysics toolbox. Spat Vis 10:433-436.

Bressler SL, Tang W, Sylvester CM, Shulman GL, Corbetta M (2008) Topdown control of human visual cortex by frontal and parietal cortex in anticipatory visual spatial attention. J Neurosci 28:10056-10061.

Cools R, Clark L, Robbins TW (2004) Differential responses in human striatum and prefrontal cortex to changes in object and rule relevance. J Neurosci 24:1129-1135.

Cools R, Ivry RB, D'Esposito M (2006) The human striatum is necessary for responding to changes in stimulus relevance. J Cogn Neurosci 18:1973-1983.

Cools R, Gibbs SE, Miyakawa A, Jagust W, D’Esposito M (2008) Working memory capacity predicts dopamine synthesis capacity in the human striatum. J Neurosci 28:1208-1212.

Corbetta M, Shulman GL (2002) Control of goal-directed and stimulusdriven attention in the brain. Nat Rev Neurosci 3:201-215.

Corbetta M, Miezin FM, Shulman GL, Petersen SE (1993) A PET study of visuospatial attention. J Neurosci 13:1202-1226.

Corbetta M, Akbudak E, Conturo TE, Snyder AZ, Ollinger JM, Drury HA, Linenweber MR, Petersen SE, Raichle ME, Van Essen DC, Shulman GL (1998) A common network of functional areas for attention and eye movements. Neuron 21:761-773.

Corbetta M, Kincade JM, Ollinger JM, McAvoy MP, Shulman GL (2000) Voluntary orienting is dissociated from target detection in human posterior parietal cortex. Nat Neuroscience 3:292-297.

Corbetta M, Kincade JM, Shulman GL (2002) Neural systems for visual orienting and their relationships to spatial working memory. J Cogn Neurosci 14:508-523.

Corbetta M, Patel G, Shulman GL (2008) The reorienting system of the human brain: from environment to theory of mind. Neuron 58:306-324.

Coull JT, Nobre AC (1998) Where and when to pay attention: the neural systems for directing attention to spatial locations and to time intervals as revealed by both PET and fMRI. J Neurosci 18:7426-7435.

Coull JT, Frith CD, Büchel C, Nobre AC (2000) Orienting attention in time: behavioural and neuroanatomical distinction between exogenous and endogenous shifts. Neuropsychologia 38:808-819.

de Fockert J, Rees G, Frith CD, Lavie N (2004) Neural correlates of attentional capture in visual search. J Cogn Neurosci 16:751-759.

Desimone R, Duncan J (1995) Neural mechanisms of selective visual attention. Annu Rev Neurosci 18:193-222.

Di Martino A, Scheres A, Margulies DS, Kelly AM, Uddin LQ, Shehzad Z, Biswal B, Walters JR, Castellanos FX, Milham MP (2008) Functional connectivity of human striatum: a resting state FMRI study. Cereb Cortex 18:2735-2747. 
Dosenbach NU, Visscher KM, Palmer ED, Miezin FM, Wenger KK, Kang HC, Burgund ED, Grimes AL, Schlaggar BL, Petersen SE (2006) A core system for the implementation of task sets. Neuron 50:799-812.

Downar J, Crawley AP, Mikulis DJ, Davis KD (2001) The effect of task relevance on the cortical response to changes in visual and auditory stimuli: an event-related fMRI study. Neuroimage 14:1256-1267.

Downes JJ, Sharp HM, Costall BM, Sagar HJ, Howe J (1993) Alternating fluency in Parkinson's disease. An evaluation of the attentional control theory of cognitive impairment. Brain 116:887-902.

Forman SD, Cohen JD, Fitzgerald M, Eddy WF, Mintun MA, Noll DC (1995) Improved assessment of significant activation in functional magnetic resonance imaging (fMRI): use of a cluster-size threshold. Magn Reson Med 33:636-647.

Fox MD, Corbetta M, Snyder AZ, Vincent JL, Raichle ME (2006) Spontaneous neuronal activity distinguishes human dorsal and ventral attention systems. Proc Natl Acad Sci U S A 103:10046-10051.

Frank MJ, Loughry B, O'Reilly RC (2001) Interactions between frontal cortex and basal ganglia in working memory: a computational model. Cogn Affect Behav Neurosci 1:137-160.

Friedrich FJ, Egly R, Rafal RD, Beck D (1998) Spatial attention deficits in humans: A comparison of superior parietal and temporal-parietal junction lesions. Neuropsychology 12:193-207.

Fuster JM (1989) The prefrontal cortex. New York: Raven.

Giessing C, Thiel CM, Rösler F, Fink GR (2006) The modulatory effects of nicotine on parietal cortex activity in a cued target detection task depend on cue reliability. Neuroscience 137:853-864.

Goldman-Rakic PS (1988) Topography of cognition: Parallel distributed networks in primate association cortex. Ann Rev Neurosci 11:137-156.

Goldman-Rakic PS (1995) Cellular basis of working memory. Neuron 14:477-485.

Hagler DJ Jr, Sereno MI (2006) Spatial maps in frontal and prefrontal cortex. Neuroimage 29:567-577.

Hagler DJ Jr, Riecke L, Sereno MI (2007) Parietal and superior frontal visuospatial maps activated by pointing and saccades. Neuroimage 35:1562-1577.

Hampshire A, Duncan J, Owen AM (2007) Selective tuning of the blood oxygenation level-dependent response during simple target detection dissociates human frontoparietal subregions. J Neurosci 27:6219-6223.

Hayes AE, Davidson MC, Keele SW, Rafal RD (1998) Toward a functional analysis of the basal ganglia. J Cogn Neurosci 10:178-198.

He BJ, Snyder AZ, Vincent JL, Epstein A, Shulman GL, Corbetta M (2007) Breakdown of functional connectivity in frontoparietal networks underlies behavioral deficits in spatial neglect. Neuron 53:905-918.

Hikosaka O, Wurtz RH (1983) Visual and oculomotor functions of monkey substantia nigra pars reticulata. I. Relation of visual and auditory responses to saccades. J Neurophysiol 49:1230-1253.

Hikosaka O, Sakamoto M, Usui S (1989) Functional properties of monkey caudate neurons I. Activities related to saccadic eye movements. J Neurophysiol 61:780-798.

Hopfinger JB, Buonocore MH, Mangun GR (2000) The neural mechanisms of top-down attentional control. Nat Neurosci 3:284-291.

Horvitz JC (2000) Mesolimbocortical and nigrostriatal dopamine responses to salient non-reward events. Neuroscience 96:651-656.

Indovina I, Macaluso E (2007) Dissociation of stimulus relevance and saliency factors during shifts of visuospatial attention. Cereb Cortex 17:1701-1711.

Jack AI, Patel GH, Astafiev SV, Snyder AZ, Akbudak E, Shulman GL, Corbetta M (2007) Changing human visual field organization from early visual to extra-occipital cortex. PLoS ONE 2:e452.

Kastner S, Ungerleider LG (2000) Mechanisms of visual attention in the human cortex. Annu Rev Neurosci 23:315-341.

Kastner S, Pinsk MA, De Weerd P, Desimone R, Ungerleider LG (1999) Increased activity in human visual cortex during directed attention in the absence of visual stimulation. Neuron 22:751-761.

Kelley TA, Serences JT, Giesbrecht B, Yantis S (2008) Cortical mechanisms for shifting and holding visuospatial attention. Cereb Cortex 18:114-125.

Kerr DL, Gusnard DA, Snyder AZ, Raichle ME (2004) Effect of practice on reading performance and brain function. Neuroreport 15:607-610.

Kincade JM, Abrams RA, Astafiev SV, Shulman GL, Corbetta M (2005) An event-related functional magnetic resonance imaging study of voluntary and stimulus-driven orienting of attention. J Neurosci 25:4593-4604.

Lewis SJ, Dove A, Robbins TW, Barker RA, Owen AM (2004) Striatal con- tributions to working memory: a functional magnetic resonance imaging study in humans. Eur J Neurosci 19:755-760.

Macaluso E, Frith CD, Driver J (2002) Supramodal effects of covert spatial orienting triggered by visual or tactile events. J Cogn Neurosci 14:389-401.

Marois R, Leung HC, Gore JC (2000) A stimulus-driven approach to object identity and location processing in the human brain. Neuron 25:717-728.

Mayr U, Diedrichsen J, Ivry R, Keele SW (2006) Dissociating task-set selection from task-set inhibition in the prefrontal cortex. J Cogn Neurosci 18:14-21.

McNab F, Klingberg T (2008) Prefrontal cortex and basal ganglia control access to working memory. Nat Neurosci 11:103-107.

Middleton FA, Strick PL (2002) Basal-ganglia 'projections' to the prefrontal cortex of the primate. Cereb Cortex 12:926-935.

Miller EK, Cohen JD (2001) An integrative theory of prefrontal cortex function. Annu Rev Neurosci 24:167-202.

Molenberghs P, Mesulam MM, Peeters R, Vandenberghe RR (2007) Remapping attentional priorities: differential contribution of superior parietal lobule and intraparietal sulcus. Cereb Cortex 17:2703-2712.

Monchi O, Petrides M, Petre V, Worsley K, Dagher A (2001) Wisconsin Card Sorting revisited: distinct neural circuits participating in different stages of the task identified by event-related functional magnetic resonance imaging. J Neurosci 21:7733-7741.

Moore T, Armstrong KM (2003) Selective gating of visual signals by microstimulation of frontal cortex. Nature 421:370-373.

Nobre AC, Sebestyen GN, Gitelman DR, Mesulam MM, Frackowiack RS, Frith CD (1997) Functional localization of the system for visuospatial attention using positron emission tomography. Brain 120:515-533.

Nobre AC, Coull JT, Frith CD, Mesulam MM (1999) Orbitofrontal cortex is activated during breaches of expectation in tasks of visual attention. Nat Neurosci 2:11-12.

Ollinger JM, Shulman GL, Corbetta M (2001) Separating processes within a trial in event-related functional MRI I. The method. Neuroimage 13:210-217.

Owen AM, Roberts AC, Hodges JR, Summers BA, Polkey CE, Robbins TW (1993) Contrasting mechanisms of impaired attentional set-shifting in patients with frontal lobe damage or Parkinson's disease. Brain 116:1159-1175.

Parent A, Hazrati LN (1995) Functional anatomy of the basal ganglia. I. The cortico-basal ganglia-thalamo-cortical loop. Brain Res Brain Res Rev 20:91-127.

Pelli DG (1997) The VideoToolbox software for visual psychophysics: transforming numbers into movies. Spat Vis 10:437-442.

Posner MI, Cohen Y (1984) Components of visual orienting. In: Attention and performance X (Bouma H, Bowhuis D, eds), pp 531-556. Hillsdale, NJ: Erlbaum.

Posner MI, Walker JA, Friedrich FJ, Rafal RD (1984) Effects of parietal injury on covert orienting of attention. J Neurosci 4:1863-1874.

Postuma RB, Dagher A (2006) Basal ganglia functional connectivity based on a meta-analysis of 126 positron emission tomography and functional magnetic resonance imaging publications. Cereb Cortex 16:1508-1521.

Prodoehl J, Yu H, Little DM, Abraham I, Vaillancourt DE (2008) Region of interest template for the human basal ganglia: comparing EPI and standardized space approaches. Neuroimage 39:956-965.

Redgrave P, Prescott TJ, Gurney K (1999a) Is the short-latency dopamine response too short to signal reward error? Trends Neurosci 22:146-151.

Redgrave P, Prescott TJ, Gurney K (1999b) The basal ganglia: a vertebrate solution to the selection problem? Neuroscience 89:1009-1023.

Ruff CC, Blankenburg F, Bjoertomt O, Bestmann S, Freeman E, Haynes JD, Rees G, Josephs O, Deichmann R, Driver J (2006) Concurrent TMSfMRI and psychophysics reveal frontal influences on human retinotopic visual cortex. Curr Biol 16:1479-1488.

Saygin AP, Sereno MI (2008) Retinotopy and attention in human occipital, temporal, parietal, and frontal cortex. Cereb Cortex 18:2158-2168.

Schluppeck D, Glimcher P, Heeger DJ (2005) Topographic organization for delayed saccades in human posterior parietal cortex. J Neurophysiol 94:1372-1384.

Schultz W (1998) Predictive reward signal of dopamine neurons. J Neurophysiol 80:1-27.

Seeley WW, Menon V, Schatzberg AF, Keller J, Glover GH, Kenna H, Reiss AL, Greicius MD (2007) Dissociable intrinsic connectivity networks for salience processing and executive control. J Neurosci 27:2349-2356. 
Serences JT, Yantis S (2006a) Selective visual attention and perceptual coherence. Trends Cogn Sci 10:38-45.

Serences JT, Yantis S (2006b) Spatially selective representations of voluntary and stimulus-driven attentional priority in human occipital, parietal, and frontal cortex. Cereb Cortex 17:284-293.

Serences JT, Shomstein S, Leber AB, Golay X, Egeth HE, Yantis S (2005) Coordination of voluntary and stimulus-driven attentional control in human cortex. Psychol Sci 16:114-122.

Sereno MI, Pitzalis S, Martinez A (2001) Mapping of contralateral space in retinotopic coordinates by a parietal cortical area in humans. Science 294:1350-1354

Silver MA, Ress D, Heeger DJ (2005) Topographic maps of visual spatial attention in human parietal cortex. J Neurophysiol 94:1358-1371.

Swisher JD, Halko MA, Merabet LB, McMains SA, Somers DC (2007) Visual topography of human intraparietal sulcus. J Neurosci 27:5326-5337.

Sylvester CM, Shulman GL, Jack AI, Corbetta M (2007) Asymmetry of anticipatory activity in visual cortex predicts the locus of attention and perception. J Neurosci 27:14424-14433.
Talairach J, Tournoux P (1988) Co-planar stereotaxic atlas of the human brain. New York: Thieme Medical.

Thiel CM, Zilles K, Fink GR (2004) Cerebral correlates of alerting, orienting and reorienting of visuospatial attention: an event-related fMRI study. Neuroimage 21:318-328.

Vandenberghe R, Duncan J, Dupont P, Ward R, Poline JB, Bormans G, Michiels J, Mortelmans L, Orban GA (1997) Attention to one or two features in left and right visual field: a positron emission tomography study. J Neurosci 17:3739-3750.

Van Essen DC (2005) A population-average, landmark- and surface-based (PALS) atlas of human cerebral cortex. Neuroimage 28:635-662.

Yantis S, Schwarzbach J, Serences JT, Carlson RL, Steinmetz MA, Pekar JJ, Courtney SM (2002) transient neural activity in human parietal cortex during spatial attention shifts. Nat Neuroscience 5:995-1002.

Zink CF, Pagnoni G, Martin ME, Dhamala M, Berns GS (2003) Human striatal response to salient nonrewarding stimuli. J Neurosci 23:8092-8097.

Zink CF, Pagnoni G, Chappelow J, Martin-Skurski M, Berns GS (2006) Human striatal activation reflects degree of stimulus saliency. Neuroimage 29:977-983. 